\title{
Evaluation of global simulations of aerosol particle and cloud condensation nuclei number, with implications for cloud droplet formation
}

George S. Fanourgakis ${ }^{1}$, Maria Kanakidou ${ }^{1}$, Athanasios Nenes ${ }^{2,3}$, Susanne E. Bauer ${ }^{4,5}$, Tommi Bergman $^{6}$, Ken S. Carslaw ${ }^{7}$, Alf Grini ${ }^{8}$, Douglas S. Hamilton ${ }^{9}$, Jill S. Johnson ${ }^{7}$, Vlassis A. Karydis ${ }^{10,11}$, Alf Kirkevåg ${ }^{12}$, John K. Kodros ${ }^{13}$, Ulrike Lohmann ${ }^{14}$, Gan Luo ${ }^{15}$, Risto Makkonen ${ }^{16,17}$, Hitoshi Matsui ${ }^{18}$, David Neubauer ${ }^{14}$, Jeffrey R. Pierce ${ }^{13}$, Julia Schmale ${ }^{19}$, Philip Stier ${ }^{20}$, Kostas Tsigaridis ${ }^{5,4}$, Twan van Noije ${ }^{6}$, Hailong Wang ${ }^{21}$, Duncan Watson-Parris ${ }^{20}$, Daniel M. Westervelt ${ }^{22,4}$, Yang Yang ${ }^{21}$, Masaru Yoshioka ${ }^{7}$, Nikos Daskalakis ${ }^{23}$, Stefano Decesari ${ }^{24}$, Martin Gysel-Beer ${ }^{19}$, Nikos Kalivitis ${ }^{1}$, Xiaohong Liu $^{25}$, Natalie M. Mahowald ${ }^{9}$, Stelios Myriokefalitakis $^{26}$, Roland Schrödner ${ }^{27}$, Maria Sfakianaki ${ }^{1}$, Alexandra P. Tsimpidi ${ }^{10}$, Mingxuan Wu ${ }^{25}$, and Fangqun $\mathbf{Y u}^{15}$

${ }^{1}$ Environmental Chemical Processes Laboratory, Department of Chemistry, University of Crete, Heraklion, 70013, Greece

${ }^{2}$ Laboratory of Atmospheric Processes and their Impacts, School of Architecture, Civil \& Environmental Engineering,

École Polytechnique Federale de Lausanne, Lausanne, 1015, Switzerland

${ }^{3}$ Institute of Chemical Engineering Sciences, Foundation for Research and Technology (FORTH/ICE-HT), Hellas, 26504,

Patras, Greece

${ }^{4}$ NASA Goddard Institute for Space Studies, New York, NY, USA

${ }^{5}$ Center for Climate Systems Research, Columbia University, New York, NY, USA

${ }^{6}$ Royal Netherlands Meteorological Institute (KNMI), De Bilt, the Netherlands

${ }^{7}$ School of Earth and Environment, University of Leeds, UK

8 independent researcher

${ }^{9}$ Department of Earth and Atmospheric Sciences, Atkinson Center for a Sustainable Future, Cornell University, Ithaca, NY, USA

${ }^{10}$ Department of Atmospheric Chemistry, Max Planck Institute for Chemistry, Mainz, Germany

${ }^{11}$ Forschungszentrum Jülich, Inst Energy \& Climate Res IEK-8, 52425 Jülich, Germany

${ }^{12}$ Norwegian Meteorological Institute, Oslo, Norway

${ }^{13}$ Department of Atmospheric Science, Colorado State University, Fort Collins, Colorado, USA

${ }^{14}$ Institute for Atmospheric and Climate Science, ETH Zurich, Zurich, Switzerland

${ }^{15}$ Climate Atmospheric Sciences Research Center, of the State University of New York at Albany, Albany, 12203, New York, USA

${ }^{16}$ Climate System Research, Finnish Meteorological Institute, P.O. Box 503, 00101 Helsinki, Finland

${ }^{17}$ Institute for Atmospheric and Earth System Research/Physics, University of Helsinki, P.O. Box 64, 00014 Helsinki, Finland

${ }^{18}$ Graduate School of Environmental Studies, Nagoya University, Nagoya, Japan

${ }^{19}$ Laboratory of Atmospheric Chemistry, Paul Scherrer Institute, Villigen, Switzerland

${ }^{20}$ Atmospheric, Oceanic \& Planetary Physics, Department of Physics, University of Oxford, Oxford OX1 2JD, UK

${ }^{21}$ Atmospheric Sciences and Global Change Division, Pacific Northwest National Laboratory, Richland, Washington, USA

${ }^{22}$ Lamont-Doherty Earth Observatory, Columbia University, Palisades, NY 10964, USA

${ }^{23}$ Laboratory for Modeling and Observation of the Earth System (LAMOS) Institute of Environmental Physics (IUP), University of Bremen, Bremen, Germany

${ }^{24}$ Institute of Atmospheric Sciences and Climate, National Research Council of Italy, Via Piero Gobetti, 101, 40129 Bologna, Italy

${ }^{25}$ Department of Atmospheric Science, University of Wyoming, Laramie, Wyoming, USA 
${ }^{26}$ Institute for Environmental Research and Sustainable Development (IERSD), National Observatory of Athens, Penteli, Greece

${ }^{27}$ Centre for Environmental and Climate Research, Lund University, Lund, Sweden

Correspondence: Maria Kanakidou (mariak@uoc.gr) and Athanasios Nenes (athanasios.nenes@epfl.ch)

Received: 22 December 2018 - Discussion started: 18 January 2019

Revised: 27 April 2019 - Accepted: 24 May 2019 - Published: 8 July 2019

\begin{abstract}
A total of 16 global chemistry transport models and general circulation models have participated in this study; 14 models have been evaluated with regard to their ability to reproduce the near-surface observed number concentration of aerosol particles and cloud condensation nuclei $(\mathrm{CCN})$, as well as derived cloud droplet number concentration (CDNC). Model results for the period 2011-2015 are compared with aerosol measurements (aerosol particle number, $\mathrm{CCN}$ and aerosol particle composition in the submicron fraction) from nine surface stations located in Europe and Japan. The evaluation focuses on the ability of models to simulate the average across time state in diverse environments and on the seasonal and short-term variability in the aerosol properties.
\end{abstract}

There is no single model that systematically performs best across all environments represented by the observations. Models tend to underestimate the observed aerosol particle and $\mathrm{CCN}$ number concentrations, with average normalized mean bias (NMB) of all models and for all stations, where data are available, of $-24 \%$ and $-35 \%$ for particles with dry diameters $>50$ and $>120 \mathrm{~nm}$, as well as $-36 \%$ and $-34 \%$ for $\mathrm{CCN}$ at supersaturations of $0.2 \%$ and $1.0 \%$, respectively. However, they seem to behave differently for particles activating at very low supersaturations $(<0.1 \%)$ than at higher ones. A total of 15 models have been used to produce ensemble annual median distributions of relevant parameters. The model diversity (defined as the ratio of standard deviation to mean) is up to about 3 for simulated $\mathrm{N}_{3}$ (number concentration of particles with dry diameters larger than $3 \mathrm{~nm}$ ) and up to about 1 for simulated $\mathrm{CCN}$ in the extra-polar regions. A global mean reduction of a factor of about 2 is found in the model diversity for $\mathrm{CCN}$ at a supersaturation of $0.2 \%$ $\left(\mathrm{CCN}_{0.2}\right)$ compared to that for $\mathrm{N}_{3}$, maximizing over regions where new particle formation is important.

An additional model has been used to investigate potential causes of model diversity in $\mathrm{CCN}$ and bias compared to the observations by performing a perturbed parameter ensemble (PPE) accounting for uncertainties in 26 aerosol-related model input parameters. This PPE suggests that biogenic secondary organic aerosol formation and the hygroscopic properties of the organic material are likely to be the major sources of CCN uncertainty in summer, with dry deposition and cloud processing being dominant in winter.
Models capture the relative amplitude of the seasonal variability of the aerosol particle number concentration for all studied particle sizes with available observations (dry diameters larger than 50, 80 and $120 \mathrm{~nm}$ ). The short-term persistence time (on the order of a few days) of CCN concentrations, which is a measure of aerosol dynamic behavior in the models, is underestimated on average by the models by $40 \%$ during winter and $20 \%$ in summer.

In contrast to the large spread in simulated aerosol particle and $\mathrm{CCN}$ number concentrations, the CDNC derived from simulated CCN spectra is less diverse and in better agreement with CDNC estimates consistently derived from the observations (average NMB $-13 \%$ and $-22 \%$ for updraft velocities 0.3 and $0.6 \mathrm{~m} \mathrm{~s}^{-1}$, respectively). In addition, simulated CDNC is in slightly better agreement with observationally derived values at lower than at higher updraft velocities (index of agreement 0.64 vs. 0.65 ). The reduced spread of $\mathrm{CDNC}$ compared to that of $\mathrm{CCN}$ is attributed to the sublinear response of $\mathrm{CDNC}$ to aerosol particle number variations and the negative correlation between the sensitivities of CDNC to aerosol particle number concentration $\left(\partial N_{\mathrm{d}} / \partial N_{\mathrm{a}}\right)$ and to updraft velocity $\left(\partial N_{\mathrm{d}} / \partial w\right)$. Overall, we find that while $\mathrm{CCN}$ is controlled by both aerosol particle number and composition, $\mathrm{CDNC}$ is sensitive to $\mathrm{CCN}$ at low and moderate $\mathrm{CCN}$ concentrations and to the updraft velocity when $\mathrm{CCN}$ levels are high. Discrepancies are found in sensitivities $\partial N_{\mathrm{d}} / \partial N_{\mathrm{a}}$ and $\partial N_{\mathrm{d}} / \partial w$; models may be predisposed to be too "aerosol sensitive" or "aerosol insensitive" in aerosol-cloud-climate interaction studies, even if they may capture average droplet numbers well. This is a subtle but profound finding that only the sensitivities can clearly reveal and may explain intermodel biases on the aerosol indirect effect.

\section{Introduction}

Aerosol particles absorb and scatter radiation, thereby modulating the planetary radiative balance (Boucher et al., 2013; Myhre et al., 2013). They also provide the nuclei upon which cloud droplets and ice crystals form; variations thereof can profoundly impact cloud formation and precipitation. Both the direct radiative effects of aerosols and their impacts on clouds are thought to be important for climate at global and regional scales, although they are highly uncertain and 
confound projections of anthropogenic climate change (e.g., Boucher et al., 2013; Seinfeld et al., 2016). The impacts of aerosols on clouds in particular introduce considerable uncertainty in our estimates of equilibrium climate sensitivity and transient climate response to the combined changes in aerosol and greenhouse gas concentrations (e.g., Seinfeld et al., 2016; Fan et al., 2016).

Aerosols can be either directly emitted from a variety of sources (primary aerosols) or formed by nucleation from precursor compounds (secondary aerosols), which afterwards can grow by condensation and coagulation from a few nanometers to a few hundred nanometers (Kerminen et al., 2012). Note that secondary aerosol also includes the condensed material upon primary emitted aerosol. Aerosols that have the potential to create cloud droplets at atmospherically relevant conditions are termed cloud condensation nuclei (CCN). The $\mathrm{CCN}$ number concentration depends on the particle size distribution, chemical composition and mixing state, as well as the level of water vapor supersaturation that develops in rising air parcels (Köhler, 1936; Seinfeld and Pandis, 2006). It is now established that primary emissions of particulate matter and particle formation from anthropogenic precursor gases have strongly modulated clouds and climate at the global scale since the industrial revolution (Boucher et al., 2013). Much work remains, however, to reduce the uncertainty associated with anthropogenic aerosol-cloud-climate interactions.

Among the main sources of uncertainty in simulating aerosol microphysics at regional to global scales are the amounts of particle and precursor vapor mass emitted by anthropogenic activities or natural sources, as well as the size distribution of the emitted particles and their representation in models. However, Mann et al. (2012) showed that a careful choice of the aerosol parameters describing the aerosol distribution can reduce differences between the sectional and the modal description of aerosol microphysics in most parts of the atmosphere. Furthermore, carbonaceous combustion aerosol, although assumed hydrophobic upon emission, was found to contribute up to $64 \%$ of global surface CCN concentrations (Spracklen et al., 2011). Although less important than particle size for $\mathrm{CCN}$ formation, particle chemical composition determines aerosol hygroscopicity (Twomey, 1977; Dusek et al., 2006; Petters and Kreidenweis, 2007; Cubison et al., 2008; Bougiatioti et al., 2009). An adequate description of aerosol hygroscopicity is required to accurately describe $\mathrm{CCN}$ and cloud droplet number variability. In this respect, uncertainties are partially related to organic aerosol (OA), which can be composed of thousands of compounds with different physical and chemical properties. OA contributes to the fine aerosol mass by up to $30 \%-70 \%$ depending on location and season (Kanakidou et al., 2005; Jimenez et al., 2009), while source estimates of OA span 1 order of magnitude (see the AEROCOM phase II intercomparison study of 31 models by Tsigaridis et al., 2014). Regionally, sea salt (SS) and mineral dust (DU) are also significant contributors to the total aerosol particle mass and number concentration. Atmospheric mass loads during the first phase of AEROCOM showed a high diversity among 15 models of $54 \%$ for SS and $40 \%$ for DU (Textor et al., 2006). This diversity arises from the different parameterizations used to calculate the size-resolved fluxes and their dependence on wind speed but also from the consideration, or not, of the supercoarse aerosol fraction (Huneeus et al., 2011; Tsigaridis et al., 2013). Although nitrate $\left(\mathrm{NO}_{3}^{-}\right)$and ammonium $\left(\mathrm{NH}_{4}^{+}\right)$ are not explicitly studied here, differences of up to a factor of 13 in the atmospheric burden of $\mathrm{NO}_{3}^{-}$and 17 and 4 for $\mathrm{NH}_{3}$ and $\mathrm{NH}_{4}^{+}$, respectively, have been found between $\mathrm{AE}$ ROCOM models (Bian et al., 2017).

Formation of new particles by nucleation in the atmosphere is a frequent phenomenon in the free troposphere and in the continental boundary layer (e.g., Kerminen et al., 2010; Kulmala and Kerminen, 2008), and it is an important source of aerosol particle number on a global scale (Kerminen et al., 2012; Kalivitis et al., 2015; Gordon et al., 2017). Although it is well established that sulfuric acid, due to its low volatility, plays a central role in new particle formation and growth, it cannot explain the observed substantial growth of small particles in many environments where organics and $\mathrm{NH}_{3}$ are abundant. This is due to the low concentration of sulfuric acid and is evidenced by the observed poor correlation of its concentration with very small particles (e.g., Pierce et al., 2011). Recently, the involvement of organics from early stages of nucleation and growth of particles has been established (e.g., D'Andrea et al., 2013; Spracklen et al., 2008; Makkonen et al., 2009; Tröstl et al., 2016). Several approaches for modeling particle growth in large-scale models have been developed, which are very sensitive to the volatility of organic vapor (e.g., Laaksonen et al., 2008; Yu, 2011; D’Andrea et al., 2013) and are being implemented in global models.

The number concentration and the size of cloud droplets depend on both the concentrations of CCN and on the cloud updraft velocity (Pruppacher and Klett, 1997; Seinfeld and Pandis, 2006). However, the spatial scale of updrafts governing droplet formation is several orders of magnitude smaller than the size of the grid boxes of global models. Therefore, parameterized aerosol-cloud interactions in climate models require sub-grid-scale vertical velocity distributions to calculate grid-scale relevant cloud droplet number concentration (CDNC) (Morales and Nenes, 2010). Karydis et al. (2012) and Moore et al. (2013) have shown that in regions with low particle number concentrations, such as the Arctic and remote oceans, $\mathrm{CDNC}$ is more sensitive to $\mathrm{CCN}$ uncertainty than in continental regions where particle number concentrations exceed $10^{4} \mathrm{~cm}^{-3}$. In contrast, Ervens et al. (2010) pointed out that at high updraft velocities, supersaturation is controlled by adiabatic cooling, and CDNC is not very sensitive to errors in simulated CCN number concentration. They estimated that uncertainties in the chemical composition of aerosol particles that could lead to a doubling of CCN concentration would affect CDNC by only about $10 \%-$ 
$20 \%$. Therefore, there are two distinct regimes with regard to CDNC sensitivity: aerosol limited and updraft velocity limited (Reutter et al., 2009).

Totally different cloud radiative (indirect) effects could be computed by climate models depending on the dominance of CDNC sensitivity to either aerosol number or updraft velocity (Sullivan et al., 2016). Therefore, capturing the balance between the two is critical in understanding where and when aerosol emissions are governing the variability of cloud properties and where the updraft velocity is the controlling factor. The failure of state-of-the-art models to capture such sensitivity implies that even if models exhibit a similar magnitude of aerosol indirect effects, it may be for completely different reasons (Sullivan et al., 2016). In this case models would show limited skills and their predictions would be associated with low confidence.

The aims of this work are to (i) assess the accuracy of state-of-the-art global aerosol models in simulating the chemical composition and number concentration of aerosol particles, with a focus on $\mathrm{CCN}$ concentrations at various water vapor supersaturation ratios, (ii) document the diversity of the global models in simulating these aerosol properties, (iii) produce an ensemble view of the global distribution of aerosol particle and $\mathrm{CCN}$ number concentrations, together with the most important particle chemical components at the Earth's surface, (iv) evaluate the agreement of inferred CDNC from modeled and from observed CCN spectra and their sensitivity to aerosol number concentrations and updraft velocities, (v) evaluate the potential causes of model diversity and bias versus observations using model uncertainty analysis, and (vi) provide recommendations for future model improvements.

A total of 16 global models contributed to this study, and multiyear observations of CCN, size-resolved particle number concentration distributions, and particle chemical composition obtained from eight atmospheric monitoring stations in Europe and one in Japan were used as an observational reference, representing distinct atmospheric environments (Schmale et al., 2017, 2018).

\section{Methodology}

\subsection{Contributing models and model description}

Model setup, such as spatial resolution, meteorological conditions and emission inventories, differs significantly among models (Tables S1 to S4 in the Supplement). The spatial resolution varies among the models from $0.94^{\circ}$ by $1.3^{\circ}$ to $4^{\circ}$ by $5.0^{\circ}$ (latitude by longitude) and from 25 to 56 vertical layers up to 10 and even $0.1 \mathrm{hPa}$. Nine of the models are general circulation models (GCMs) and six are chemical transport models (CTMs). The CTMs use prescribed (and different) meteorological datasets, while the GCMs (with the exception of GISS-E2-TOMAS) are nudged to various reanalysis products. Atmospheric transport, secondary aerosol formation and removal of aerosols are driven by wind, temperature, radiation, precipitation and relative humidity, as well as cloud fraction and liquid water content. In addition, most of the models use wind-driven dust, sea salt and marine organic aerosol emissions as well as calculated online biogenic emissions of non-methane volatile organic compounds (NMVOCs) (Table S3). Therefore, meteorology significantly affects number concentration, composition and other metrics of aerosol particles.

Despite the recognized importance of organic compounds in nucleation (Tröstl et al., 2016), several global models that participated in the present study use the binary homogeneous nucleation of sulfuric acid and water (referred to later as BHN; e.g., Kulmala et al., 1998; Vehkamäki, 2002) and the contribution of organics to particle growth (see Sect. S1 and Table S2 and references therein). GEOS-Chem-TOMAS assumes a ternary nucleation mechanism when $\mathrm{NH}_{3}$ is present and a binary one when $\mathrm{NH}_{3}$ is absent. GEOS-Chem-APM and CAM5-Chem-APM employ a ternary ion-mediated nucleation (TIMN) scheme that considers both binary and ternary as well as ion-mediated and neutral nucleation (Yu et al., 2018). New particle formation in TM5 is calculated as a combination of BHN and organic-sulfuric acid nucleation (Riccobono et al., 2014).

Once in the atmosphere, aerosols undergo transformations through chemical and physical processes, such as coagulation, condensation and evaporation, that modify their size and physical and chemical properties. These aerosol microphysical processes are parameterized differently in models. Eight of the models use modal schemes in which the evolution of particle number and mass concentrations is described by lognormal distributions, and the remaining models use the sectional approach with various numbers of monodisperse size bins describing aerosol particle number concentration and chemical composition (Table S2).

Regarding the eight modal models, six of them (the three ECHAM models, EMAC, TM4-ECPL and TM5) are based on the M7 aerosol module developed by Vignati et al. (2004) for the description of aerosol microphysics or improved versions of $\mathrm{M} 7$ to account for $\mathrm{SO}_{2}$ oxidation to sulfuric acid, the contribution of organics to growth and additional aerosol species. Other aerosol microphysics modules used in models participating in this study are the Modal Aerosol Modules (MAM3 and MAM4; Liu et al., 2012, 2016), the Advanced Particle Microphysics (APM) package (Yu and Luo, 2009; Yu, 2011; Yu et al., 2018), the TwO-Moment Aerosol Sectional (TOMAS) microphysics package (Adams and Seinfeld, 2002), the Multiconfiguration Aerosol Tracker of mIXing state (MATRIX) module (e.g., Bauer et al., 2008), the Aerosol Two-dimensional bin module for formation and Aging Simulation version 2 (ATRAS2; Matsui, 2017) and a production-tagged module OsloAero5.3 used in combination with the offline microphysics scheme AeroTab5.3 (Kirkevåg et al., 2018). Tables S1, S2, S3 and S4 provide a summary of 
the main features of the participating models and appropriate references.

Relevant to this study are also differences in the aerosol components that are taken into consideration in the models for the CCN calculations. Nine models (CAM5-MAM3, CAM5-MAM4, CAM5.3-Oslo, the three ECHAM models, GEOS-Chem-TOMAS, GISS-E2-TOMAS models and TM4-ECPL) do not account for particulate nitrate at all or in the CCN calculations (Table S2). TM4-ECPL, however, computes the $\mathrm{NO}_{3}^{-}$and $\mathrm{NH}_{4}^{+}$mass distribution in fine and coarse modes with the ISORROPIA II module (Fountoukis and Nenes, 2007). Similarly, TM5 uses EQSAM (Metzger et al., 2002b, a) to calculate, using a bulk aerosol approach, the partitioning of ammonium nitrate between the gaseous and particulate phase with the particulate mass assumed to reside in the soluble accumulation mode.

Both dry deposition and wet deposition of aerosol particles are taken into account in the participating models as shown in Table S4. For dry deposition, models account for gravitational settling and for turbulence, and thus these processes depend on the aerosol particle size. The omission of super-coarse particle sources associated with dust and seasalt particles results in discrepancies between models and between model results and observations (Myriokefalitakis et al., 2016). Wet deposition parameterizations account for both in-cloud scavenging, which is sensitive to the solubility of aerosol particles, and below-cloud scavenging by convective and large-scale precipitation (Seinfeld and Pandis, 2006). In addition, while all models account for in-cloud scavenging of aerosols and for aerosol release from the evaporation of droplets, a few models also account for melting and sublimation of ice crystals. For the calculation of $\mathrm{CCN}$ concentrations from the aerosol number and mass distributions, models need to specify their hygroscopicity from the volumeweighted hygroscopicities of each constituent (Table 1) following the approach of Petters and Kreidenweis (2007).

Furthermore, most of the participating models (Table S4) follow the AEROCOM recommendation of biomass burning emission heights, which in the boreal regions extend above $2 \mathrm{~km}$ and up to $6 \mathrm{~km}$ for the Canadian boreal fires (Dentener et al., 2006). ECHAM6-HAM2 and ECHAM6-HAM2-AP use a slightly different vertical distribution of biomass burning emissions, with $75 \%$ within the planetary boundary layer (PBL), $17 \%$ in the first and $8 \%$ in the second level above the PBL (Tegen et al., 2019). EMAC assumes biomass burning emissions at $140 \mathrm{~m}$ and GEOS-Chem-APM well mixed in the boundary layer.

In addition to these 15 models, we include the results from perturbed parameter ensemble (PPE) simulations using HadGEM3-UKCA (Yoshioka et al., 2019; see details in Sect. S1). The PPE consists of 235 atmosphere-only simulations for the year 2008 with 26 parameters controlling aerosol emissions and processes perturbed simultaneously. Simulations were nudged to ERA-Interim wind and temperature and all aerosol feedbacks to atmospheric dynamics are

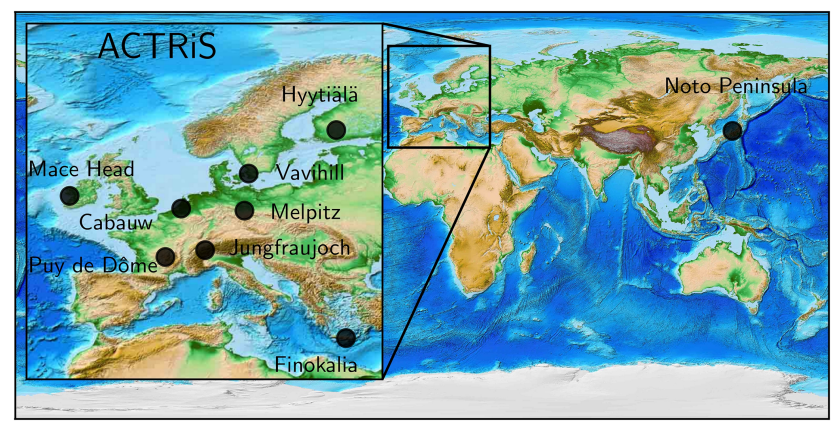

Figure 1. Map showing the location of the measurement sites used in this study.

turned off. Therefore, all simulations share the same meteorology. CCN number concentrations were calculated globally for all member simulations and taken at geographical locations and elevations of observation stations. These simulations were then used to create Gaussian process emulators at each station location from which 260000 "model variants" were generated that densely sample the 26-dimension parameter space. The emulator was validated against additional model simulations to show that the emulator uncertainty is much smaller than the model parametric uncertainty.

\subsection{Observational data for model evaluation}

Datasets for $\mathrm{CCN}$ at various supersaturations, particle number concentrations, size distributions and particle chemical compositions measured at one atmospheric monitoring station in Japan and eight Aerosols, Clouds, and Trace gases Research InfraStructure (ACTRIS) atmospheric monitoring stations in Europe (Schmale et al., 2017) were used in the present study (Fig. 1) for the evaluation of model results. The observatories are representative of different environments (Pacific, Atlantic and Mediterranean marine atmospheres, high alpine and boreal forest continental atmospheres). A brief site description of the observatories is provided in Table S5, while more technical details are given by Schmale et al. (2017). While in general measurement data are available from the period 2011 to 2015 , each station covered only a subperiod of those 5 years but at least one entire year (Schmale et al., 2017). Despite using point measurements, the long period of observations allows for the evaluation of global models without biases associated with the model resolution (Schutgens et al., 2016). Six out of the nine stations provided non-refractory chemical composition data on submicron particles (based on aerosol mass spectrometry), while all stations recorded submicron particle number size distributions and $\mathrm{CCN}$ number concentrations over a variety of supersaturations. A detailed discussion of the observational results can be found in Schmale et al. (2018).

For this study, the observations of $\mathrm{CCN}$ concentrations at supersaturations spanning between $0.1 \%$ and $1.0 \%$, the 
Table 1. Hygroscopicity parameters used by the participating models for water uptake calculations.

\begin{tabular}{lrrrrrr}
\hline Model & $\mathrm{SO} 4$ & $\mathrm{OA}$ & $\mathrm{SS}$ & $\mathrm{DU}$ & $\mathrm{BC}$ & $\mathrm{NO}_{3}$ \\
\hline CAM5-Chem-APM & 0.9 & 0.1 & 1.28 & 0 & 0 & 0.9 \\
CAM5-Chem-ATRAS2 & 0.61 & 0.1 & 1.16 & 0.001 & $1 \times 10^{-6}$ & 0.61 \\
CAM5_MAM3 & 0.507 & 0.1 & 1.16 & 0.068 & 0 & N/A \\
CAM5_MAM4 & 0.507 & 0 & 1.16 & 0.068 & & N/A \\
CAM5.3-Oslo & $0.507^{(1)}$ & 0.14 & 1.2 & 0.069 & $5 \times 10^{-7}$ & N/A \\
ECHAM5.5-HAM2-ELVOC_UH & 0.6 & 0.06 & 1.12 & 0 & & \\
ECHAM6-HAM2(2) & 0.7 & 0 & 1.3 & 0 & 0 & N/A \\
ECHAM6-HAM2-AP(2) & 0.7 & 0 & 1.3 & 0 & 0 & N/A \\
EMAC(3) & & 0.1 & 1.12 & 0 & 0 & N/A \\
GEOS-Chem-APM & 0.9 & 0.1 & 1.28 & 0 & 0 & 0.9 \\
GEOS-Chem-TOMAS & 1.0 & $0.1^{(4)}$ & 1.2 & 0.01 & 0 & N/A \\
GISS-E2.1-MATRIX & 0.507 & 0.141 & 1.335 & 0.14 & $5 \times 10^{-7}$ & 0.507 \\
GISS-E2-TOMAS & 0.7 & $0.15^{(5)}$ & 1.3 & 0 & 0 & N/A \\
TM4-ECPL & 0.6 & 0.1 & 1.0 & 0 & 0 & N/A \\
TM5 & 0.6 & 0.1 & $1.0^{(6)}$ & 0 & 0 & 0.6 \\
\hline
\end{tabular}

${ }^{1}$ In CAM5.3-Oslo the hygroscopicity parameters $\kappa$ for pure ammonium sulfate or sulfuric acid are 0.507 and 0.534 , respectively. For internal mixtures, $\kappa$ is a mass-weighted average of the aerosol components, except for particles coated $(>2 \mathrm{~nm}$ ) with SO4, OA and/or SS, where $\kappa$ is a mass-weighted average of the components of the coating (Kirkevåg et al., 2018). ${ }^{2}$ ECHAM6-HAM2 and ECHAM6-HAM2-AP use the Abdul-Razzak and Ghan (AR-G) activation scheme (Abdul Razzak and Ghan, 2000). The reported values are approximated using the number of ions and osmotic coefficients used in the AR-G scheme. ${ }^{(3)}$ EMAC model simulates the effective hygroscopicity parameter $\kappa$ of each aerosol size mode in order to describe the influence of chemical composition on the CCN activity of aerosol particles (Pringle et al., 2010). These values are the internally mixed $\kappa$ calculated across the nucleation, Aitken, accumulation and coarse modes. The effective aerosol hygroscopicity parameter $\kappa$ is calculated according to the simple mixing rule proposed by Petters and Kreideweis (2007) using the volume fraction and hygroscopicity parameter of each chemical component ( 23 salts from ISORROPIA-II and 4 bulk species) taken from Petters et al. (2007) and Sullivan et al. (2009) ${ }^{(4)}$ for hydrophilic OA $\kappa=0.1$, for hydrophobic OA $\kappa=0.01$ and ${ }^{(5)}$ for hydrophilic ORG (Lee et al., 2015). For hydrophobic, $\kappa=0$. ${ }^{(6)}$ for $\mathrm{NaCl} \kappa=1$, for $\mathrm{Na}_{2} \mathrm{SO}_{4} \kappa=0.95$. N/A: not considered in this study.

number concentrations of aerosols with dry diameters larger than 50, 80 and $120 \mathrm{~nm}$ (denoted hereafter as $\mathrm{N}_{50}, \mathrm{~N}_{80}$ and $\mathrm{N}_{120}$, respectively), and $\mathrm{PM}_{1}$ (particles with dry diameters less than $1 \mu \mathrm{m}$ ) chemical composition (mainly sulfate $\left(\mathrm{SO}_{4}^{2-}\right.$, hereafter SO4) and organic aerosol - OA) from the nine stations are used. The $\mathrm{CCN}$ data for these stations cover at least $75 \%$ of each year (Schmale et al., 2017). Observational data have been further filtered so that there is a minimum data requirement, which means that daily averages are calculated from hourly data only for days with at least six hourly measurements. Monthly averages follow a similar method, whereby the average is calculated only for months with at least 10 daily averages. When fewer data are available, the data are not considered representative of this quantity and are not included in the comparisons with the model results.

\subsection{Design of the experiment}

This model experiment has been designed within the BACCHUS EU project and has been opened for participation to the entire AEROCOM global modeling community. Global simulations have been performed for the years 2010-2015 (2010 is used as a spin-up). SO4, BC, OA, SS and DU are the aerosol components that are considered here. Models provided hourly values for $\mathrm{N}_{50}, \mathrm{~N}_{80}, \mathrm{~N}_{120}$ and $\mathrm{CCN}$ number concentrations for 13 supersaturations ranging from $0.05 \%$ up to $1.0 \%$ (these are $0.05 \%, 0.075 \%, 0.1 \%, 0.15 \%$ and from $0.2 \%$ to $1.0 \%$ in increments of $0.1 \%$, denoted hereafter as $\mathrm{CCN}_{i}$, where $i$ is the supersaturation value), as well as the chemical composition of $\mathrm{PM}_{1}$ particles at the station locations (Table S5). The large number of different supersaturations at which CCN are computed allows for direct comparisons with all available observations of $\mathrm{CCN}$ for the nine stations as well as for the calculation of CDNC (Sect. 2.4). Among the models that participated in the present study GISS-E2-TOMAS and HadGEM3-UKCA did not provide any results for the stations due to meteorology not corresponding to the measurement time period (free running for the first one and 2008 for the second); therefore, all multimodel medians (MMMs) for the stations presented below have been computed excluding these models.

Beyond station data, the global annual mean surface distribution of $\mathrm{CCN}_{0.2}$, the particle numbers $\mathrm{N}_{3}, \mathrm{~N}_{50}$ and $\mathrm{N}_{120}$, and the mass composition of the $\mathrm{PM}_{1}$ particles for the year 2011 are provided by 15 models (HadGEM3-UKCA did not provide such results). The MMM has been computed as the median of the contributing models.

In addition to the data provided by the 15 global models, the results of the PPE using HadGEM3-UKCA (Yoshioka et al., 2019) are used in this study to quantify the model parametric uncertainty in $\mathrm{CCN}$ and to perform a sensitivity analy- 
sis to quantify how each parameter contributes to the overall uncertainty.

\subsection{Data interpretation methodology}

\subsubsection{CCN persistence}

To investigate the duration for which the $\mathrm{CCN}$ number concentration remains similar to its earlier concentration, the so-called persistence, the autocorrelation function (ACF) of the CCN time series, has been calculated as in Schmale et al. (2018) (see also Sect. S2). This ACF may provide valuable information about the drivers of the variability of the $\mathrm{CCN}$ number concentration in the atmosphere. In the present study, we chose to compute the ACF based on model results of $\mathrm{CCN}_{0.2}$ at the nine sampling sites and compare them with the corresponding ACF obtained from observations (Schmale et al., 2018). For a direct comparison, we use the same time periods as for the observations, which vary among the sampling sites. For all ACF calculations, hourly data on $\mathrm{CCN}_{0.2}$ were used for both the observations and model results.

\subsubsection{CDNC calculations}

While GCMs calculate CDNC using a variety of approaches, for the present study CDNC is calculated offline using a common parameterization for $\mathrm{CCN}$ spectra derived from the models or from the observations. This approach allows for an understanding of the importance of differences in modeled and observed CCN spectra by expressing them as differences in CDNC that would form in a given type of cloud. We have calculated CDNC for two different updraft velocities: one characteristic for stratiform clouds $\left(w=0.3 \mathrm{~m} \mathrm{~s}^{-1}\right)$ and the second characteristic for cumulus clouds $\left(w=0.6 \mathrm{~m} \mathrm{~s}^{-1}\right)$, where $w$ is the width of the vertical velocity distribution assuming a zero mean Gaussian. Similar calculations have been performed using the observed CCN spectra at the stations where such information is available to enable comparison of model results with observations. The ability of the modeled CCN spectra to reproduce the observed sensitivity of CDNC to aerosol or to updraft velocity is also evaluated. Note that evaluation of the differences in CDNC calculations by the different models that are derived from both the parameterizations used and from their input variables would require a different model intercomparison design than here and is planned for the future. Morales Betancourt and Nenes (2014a) provide a good example in which the source of CDNC prediction discrepancy for two state-of-the-art parameterizations in the CAM5 global model was unraveled using adjoint sensitivity analysis. That study pointed to exactly which aspects of the parameterization (i.e., water uptake from large $\mathrm{CCN}$ ) were not captured adequately, leading to the highly improved droplet parameterizations (Morales-Betancourt and Nenes, 2014b) that were used in the current study.
The calculation of CDNC is based on the parameterization of Nenes and Seinfeld (2003) with the mass transfer augmentations proposed by Fountoukis and Nenes (2005), Barahona and Nenes (2007), and Morales Betancourt and Nenes (2014b). Using the CCN at different supersaturations (Sect. 2.3) allows us to consistently construct the $\mathrm{CCN}$ spectrum function $F(s)$ from each simulation, which provides the $\mathrm{CCN}$ number as a function of supersaturation, $s$ (Sotiropoulou et al., 2006):

$F(s)=\frac{N}{1+\left(\frac{s}{b}\right)^{a}}$,

where $N$ is the total number of particles, and $a$ and $b$ are parameters determined using a nonlinear fitting procedure for each of the participating models. $F(s)$ is then computed for each station's grid point and time step of the model outputs (with $b$ and $a$ being fitting parameters), and CDNC, denoted in the figures by $N_{\mathrm{d}}$, is computed from the parameterization for prescribed values of the vertical velocity. This fitting approach has also been applied to the $\mathrm{CCN}$ observations since they are available only for a limited number of supersaturations and thus cannot be directly used for accurate calculation of CDNC. A well-constrained $\mathrm{CCN}$ spectrum requires concentrations for at least five different supersaturations at the same time instance (Sotiropoulou et al., 2006). Such information was available only at five stations (Cabauw, Finokalia, Jungfraujoch, Mace Head and Vavihill), which is subsequently used for deriving CDNC based on observations and compared against model-derived CDNC.

The CDNC parameterization uses as input $F(s)$, cloudbase pressure and temperature, and the vertical velocity characterizing the cloud updraft (either as a single updraft or a "characteristic" value that provides a distribution-averaged value; Morales and Nenes, 2010). It determines the value of maximum supersaturation, $s_{\max }$, that develops in the cloudy updrafts using the concept of "population splitting" (Nenes and Seinfeld, 2003). $s_{\max }$ is achieved during the cloud parcel ascent and is calculated considering the water vapor balance between its availability from cooling and its loss from condensational growth of the CCN (Fountoukis and Nenes, 2005). CDNC is then obtained from the CCN spectrum as $N_{\mathrm{d}}=F\left(s_{\max }\right)$. This approach works well for stratus and stratocumulus clouds (Morales and Nenes, 2010). CDNC calculated here is from primary activation and does not consider the influence of preexisting droplets, although modifications to the parameterization can account for this as well (e.g. Barahona et al., 2014).

\subsubsection{Ensemble modeling computation}

The modeled hourly aerosol particle number concentrations, mass composition, $\mathrm{CCN}$ and $\mathrm{CDNC}$ at the nine stations have been used to calculate daily and monthly averages. Comparison of individual model results with observations is provided in Figs. S2 and S3 because it can be used to iden- 
tify the strengths and weaknesses of each specific model and can serve as a guide for model improvements in the future. In Sect. 3, the multi-model median (MMM) is compared to observations. The diversity of the model results (defined as the ratio of standard deviation to mean) and the mean of the models, which in several cases significantly differs from the MMM, are also reported in these comparisons.

Annual averages of the global surface distributions of $\mathrm{N}_{3}$, $\mathrm{N}_{50}, \mathrm{~N}_{120}, \mathrm{CCN}_{0.2}$ and $\mathrm{PM}_{1}$ mass concentrations of the major aerosol components have been provided by a total of 15 models. Global fields have first been re-gridded to a $5^{\circ} \times 5^{\circ}$ grid for all models, which is close to the coarsestresolved participating models $\left(4^{\circ} \times 5^{\circ}\right)$. Then the MMM and diversity are calculated, as described above, for the stations. Note that $5^{\circ} \times 5^{\circ}$ is a very coarse grid size, which no doubt affects the model-to-observation comparison, particularly when comparing to sites within small heavily polluted areas where a large rural background is now also being added in and vice versa. Therefore, it is worth mentioning that the surface stations used for model comparison are representative of the larger area in which they are located and justify our choice for a relatively large grid to re-grid all model results. For the mountain stations, the appropriate model level has been considered that corresponds to the station's altitude above sea level. Annual means of the individual models are also presented in Figs. S6-S14.

\subsubsection{Performance indexes}

For the comparison of model results with observations, a number of statistics variables have been calculated and defined as shown in Sect. S3.2. Hereafter we discuss the following:

the index of agreement

$$
\left(\mathrm{IoA}=1-\frac{\sum_{i=1}^{N}\left(P_{i}-O_{i}\right)^{2}}{\sum_{i=1}^{N}\left(\left|O_{i}-\bar{O}\right|+\left|P_{i}-\bar{O}\right|\right)^{2}}\right),
$$

the normalized mean bias

$$
\left(\mathrm{NMB}=\frac{\sum_{i=1}^{N}\left(P_{i}-O_{i}\right)}{\sum_{i=1}^{N} O_{i}} \times 100 \%\right)
$$

and the normalized mean error

$$
\left(\mathrm{NME}=\frac{\sum_{i=1}^{N}\left|P_{i}-O_{i}\right|}{\sum_{i=1}^{N} O_{i}} \times 100 \%\right),
$$

where $M$ represents model results, $O$ represents observations, $\bar{O}$ stands for the mean of the observations, and normalized mean bias (NMB), normalized mean error (NME) and the index of agreement (IoA) are used to quantify the performance of the models to reproduce observations. The IoA is a measure of the agreement of model results with the observations. In this study we use all three for the evaluation of the capability of the models to reproduce the observations.
We calculate also

the Pearson linear regression coefficient,

$$
\left(r=\left[\frac{\sum_{i=1}^{N}\left(P_{i}-\bar{P}\right)\left(O_{i}-\bar{O}\right)}{\sqrt{\sum_{i=1}^{N}\left(P_{i}-\bar{P}\right)^{2} \sqrt{\sum_{i=1}^{N}\left(O_{i}-\bar{O}\right)^{2}}}}\right]\right),
$$

as a measure of the ability of the model results to represent the variability in the observations.

\section{Evaluation against station observations}

\subsection{CCN number concentration comparisons with multi-model median}

The models tend to underestimate the monthly $\mathrm{CCN}_{0.2}$ number concentration in the lowest model level at all sites (Figs. 2 and S2) for the years 2011-2015: the average NMB of all models and for the nine sites is as low as $-36 \%$, and the NME is $69 \%$, while among individual models and stations NMB and NME vary from $-88 \%$ to $145 \%$ and from $40 \%$ to $159 \%$, respectively (see Sect. S3.2 for definitions and Table S6 for results). The Finokalia station is an exception, where most models overestimate $\mathrm{CCN}_{0.2}$ (average NMB around $47 \%$ ) with eight models showing significant overestimation (NMB $>10 \%$ ) and six models smaller deviations from observations $(-10 \%<\mathrm{NMB}<10 \%)$. Among the studied locations, Finokalia is the station with the highest observed critical diameter $(\sim 200 \mathrm{~nm}$ at a supersaturation of $0.2 \%$ according to Schmale et al., 2018); therefore, potential inaccuracies in the model determination of the critical size may be responsible for the model overestimate of $\mathrm{CCN}_{0.2}$ at this station.

Such a hypothesis is supported by earlier studies that have observed a large size dependence of sensitivity in the activation fraction at low supersaturations and in the size ranges between 60 and $100 \mathrm{~nm}$ (Bougiatioti et al., 2011). Deng et al. (2013) reported inferred critical diameters varying by factors of 2-3 for low supersaturations from $0.06 \%$ to $0.2 \%$ and suggested the use of size-resolved particle number concentrations with inferred critical diameters or size-resolved activation ratios to predict $\mathrm{CCN}$. Errors in $\mathrm{CCN}$ predictions have been shown to exceed $50 \%$ only at very low supersaturations (Reutter et al., 2009), reaching a factor of 2.4, while at high supersaturations CCN overestimates can be less than $5 \%$ (Ervens et al., 2007). The global near-surface mean CCN prediction error has been estimated at about $9 \%$, and regionally the maximum error can reach $40 \%$ (Sotiropoulou et al., 2007). The largest CCN prediction error was found in regions with low in-cloud $s_{\max }$, like those affected by long-range transport of pollution or industrial pollution plumes. Lower $\mathrm{CCN}$ prediction error was found in regions where in-cloud $s_{\text {max }}$ is high, which is typical for pristine areas. Sotiropoulou et al. (2007) also found that the assumption of a size-invariant 

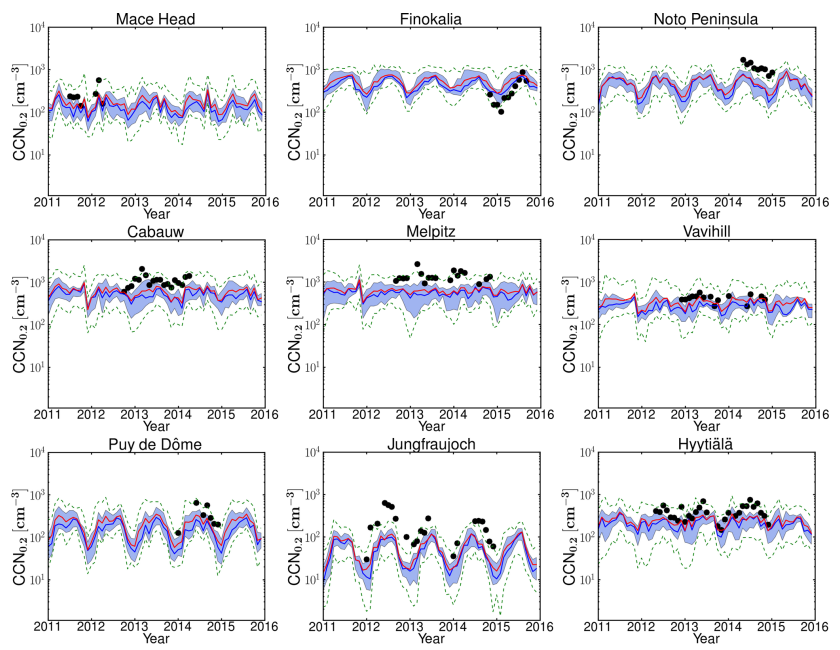

Figure 2. Monthly ensembles for the years 2011-2015 of the CCN number concentration for supersaturation $0.2 \%\left(\mathrm{CCN}_{0.2}\right)$. The $\mathrm{CCN}_{0.2}$ obtained from observational data is shown with symbols. The continuous bold blue and red lines show the monthly median and mean of all models, respectively. The shaded area shows $25 \%$ and $75 \%$ of the model results, while the green dashed lines show the minimum and maximum values of all models.

chemical composition of internally mixed aerosol increases the error by a factor of 2 .

The underestimation of the observed $\mathrm{CCN}_{0.2}$ by the models is largest at the high alpine site of Jungfraujoch (mean NMB of all models: $-73 \%$ ), where none of the models are able to capture the maximum observed values of $\mathrm{CCN}_{0.2}$ $\left(\sim 300-600 \mathrm{~cm}^{-3}\right)$ during summer. Deficiencies in the models' representation of the boundary layer and mixing of air between the boundary layer and the free troposphere in complex terrain like the Alps, as well as the sampling of the models based on the station's altitude, might be reasons for this systematic underestimation by the models (D'Andrea et al., 2016). Despite the quantitative differences in the estimation of the $\mathrm{CCN}_{0.2}$ concentrations, models are able to qualitatively capture the relative differences in $\mathrm{CCN}_{0.2}$ concentrations between stations and their seasonal variations. Comparing the $\mathrm{CCN}_{0.2}$ as calculated from the observations and as computed from the daily MMM for the days with available observations for the stations, we find a Pearson linear correlation coefficient $(r)$ that varies between 0.44 (for Melpitz) and 0.83 (for Mace Head), showing significant covariation of model results with observations. Furthermore, ranking the stations based on the observed mean $\mathrm{CCN}_{0.2}$ levels (Fig. S17) we find that the corresponding MMM mean follows this station ranking with the exception of Finokalia where, as further discussed, the models overestimate the observed $\mathrm{CCN}_{0.2}$, although they capture $(r=0.76)$ the observed temporal variability well. The MMM index of agreement (IoA) varies between 0.44 and 0.82 for the different stations, with the best for the Finokalia remote coastal sta-

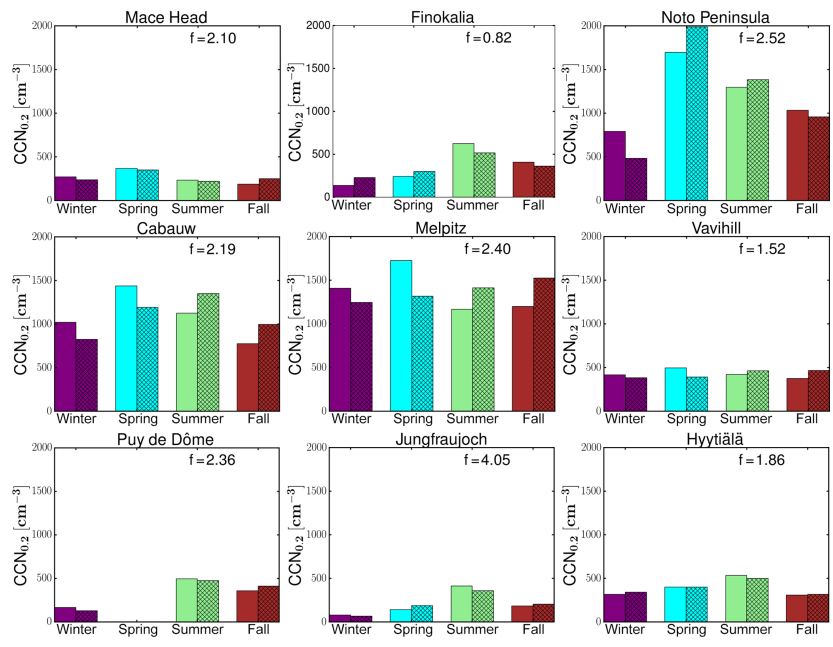

Figure 3. Comparison of the seasonal variations of the observed and model median computed $\mathrm{CCN}_{0.2}$. The solid bars show the average of the observed $\mathrm{CCN}_{0.2}$ during each season and the shaded bars the corresponding averages of the model results. The simulated $\mathrm{CCN}_{0.2}$ concentrations have been scaled by a factor, $f$ (denoted in each graph), so that the four-season mean is the same as the observed one. For Puy de Dôme the normalization is based on the mean of three seasons (winter, summer and fall) due to data availability.

tion and the worst for the Jungfraujoch alpine station. The largest difference in performance among models is found for the Mace Head station with an IoA varying between 0.20 and 0.89 for the individual models (Table S6).

To compare the calculated MMM and the observed seasonal variability of $\mathrm{CCN}_{0.2}$ for each station (Fig. 3), the monthly model results have been temporally co-located with monthly mean observations. Furthermore, to increase clarity in Fig. 3, for each station, the MMM $\mathrm{CCN}_{0.2}$ has been multiplied by a scaling factor, $f$, so that the four-season mean of the simulated MMM CCN $\mathrm{CN}_{0.2}$ concentrations becomes equal to the corresponding observed value. The factor $f$ is denoted for each station inside the frame. Overall, the seasonal pattern is nicely captured by the models, although the absolute values are underestimated everywhere $(f>1.50)$ except at Finokalia $(f=0.82)$ as discussed earlier.

For the high-altitude continental background sites (Puy de Dôme, Jungfraujoch) low number concentrations with high seasonal variability are observed (winter (DJF) minimum and summer (JJA) maximum with observed summer-to-winter ratios of 2.17 and 5.37, respectively, while the simulated MMM ratios are 3.19 and 5.58). This strong seasonality is attributed to changes in the height of the boundary layer that can affect these sites during summer but not during winter when the sites are mostly in the free troposphere (Schmale et al., 2018; Jurányi et al., 2011). At Jungfraujoch the boundary layer virtually never reaches up to the site. Instead, increased concentrations are caused by injections of boundary layer air into the lower free troposphere over the mountainous terrain. 
The free tropospheric background concentration of $\mathrm{CCN}$ is very low such that increases in the number concentration of $\mathrm{CCN}$-sized particles $(90 \mathrm{~nm}$ in diameter) are a good indicator for boundary layer influence (Herrmann et al., 2015).

On the other hand, high $\mathrm{CCN}_{0.2}$ number concentrations but low seasonal variability are found for the rural background stations of Cabauw and Melpitz, indicative of the elevated air pollution background in these regions. At these stations the highest $\mathrm{CCN}_{0.2}$ number concentrations are observed during spring, which are underestimated by the MMM. Furthermore, observations show a monotonous decrease from spring to summer and fall, while models calculated higher summertime values than in spring and fall at Cabauw and a monotonous increase from spring to fall at Melpitz. This could indicate that the models are not following the observed changes in the aerosol particle number concentration and/or the critical diameter at these stations (Schmale et al., 2018), possibly also associated with the adopted sizes in the primary aerosol emissions at these locations. At the other rural background station (Vavihill), both models and observations show lower $\mathrm{CCN}_{0.2}$ concentrations and seasonal variability than at Cabauw or Melpitz. In addition, observations indicate a higher critical diameter at Vavihill (around $120 \mathrm{~nm}$ ) than at the other two stations (around $90 \mathrm{~nm}$ ) (Schmale et al., 2018).

Different seasonal cycles are also observed among the three coastal sites Mace Head, Finokalia and the Noto Peninsula: at the Mace Head site, due to the clean marine conditions over the Atlantic Ocean (Ovadnevaite et al., 2014), low $\mathrm{CCN}_{0.2}$ concentrations are observed through the year. There, the highest concentrations are observed and simulated during spring. Both Finokalia and the Noto Peninsula are impacted by long-range transport that occurs through the free troposphere and affects the surface by mixing down into the boundary layer, and the models qualitatively reproduce the observed seasonal cycles, simulating a high variation in the number concentration over the year. At Finokalia the observed and simulated summer seasonal maximum is also attributed to biomass burning plumes from northeastern $\mathrm{Eu}-$ rope (Bougiatioti et al., 2016), while high $\mathrm{CCN}_{0.2}$ concentrations peaking in spring (observations available only for May) over the Noto Peninsula are due to pollutants originating from East Asia (Iwamoto et al., 2016; Schmale et al., 2018). However, the observed sharp decline of $\mathrm{CCN}_{0.2}$ during the spring (May) to summer transition over the Noto Peninsula is also reproduced by the models. At Finokalia the models qualitatively follow the observed seasonality, although the observed summer-to-winter ratio (4.6) is underestimated by the models (2.3; Fig. 3). This can be due to the $\mathrm{CCN}$ sensitivity to loss by deposition during winter and to OA formation and hygroscopicity during summer that combined weaken the simulated seasonality (further discussion in Sect. 5).

Finally, at Hyytiälä, on average the models calculate relatively small $\mathrm{CCN}_{0.2}$ number concentrations and a low seasonal variability with a maximum in concentrations in
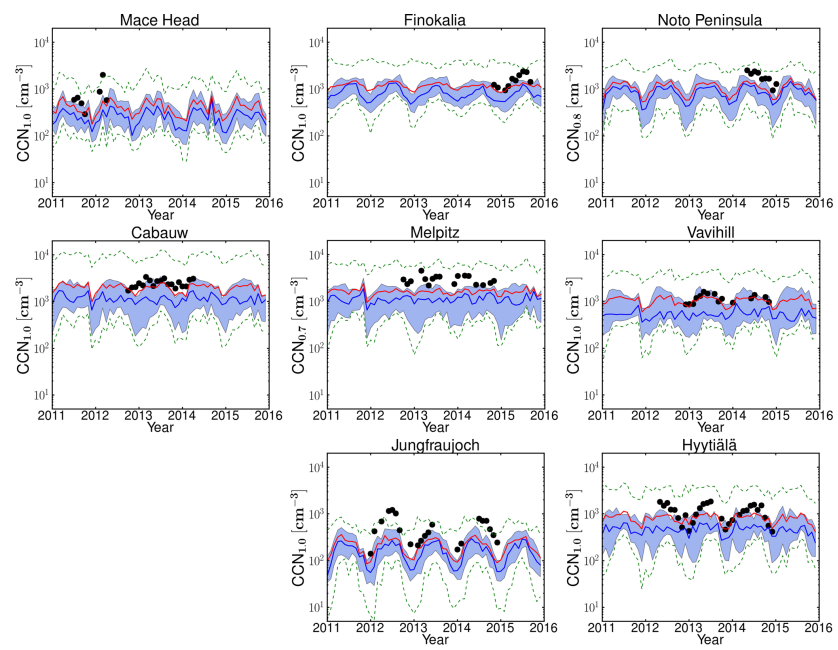

Figure 4. Same as Fig. 2 for the $\mathrm{CCN}$ at the maximum supersaturation with available measurements at each station. For Puy de Dôme only $\mathrm{CCN}_{0.2}$ data are available and are shown in Fig. 2.

summer, in agreement with observations, although they slightly underestimate the observed summer-to-winter ratio (1.5 modeled versus 1.7 observed). As discussed further in Sect. 5, at Hyytiälä the modeled $\mathrm{CCN}_{0.2}$ is very sensitive to errors in OA hygroscopicity and in secondary organic aerosol (SOA) formation from biogenic organic precursors during summer. Therefore, uncertainties in OA in the models and in particular underestimates of OA are expected to affect the summer-to-winter ratio.

Observed CCN number concentrations at the maximum supersaturation ratios measured at each station (which vary among stations, ranging from $0.7 \%$ to $1.0 \%$ ) are compared to model results in Fig. 4. CCN at various supersaturation ratios provides insights into the size distribution and the chemical composition in the models, since at high supersaturations smaller and less hygroscopic particles also activate. Most models underestimate $\mathrm{CCN}$ at high supersaturation at all stations with available observations (Fig. 4), indicating that an insufficient number of small particles are predicted to activate in the model. However, observations are captured by the maximum and minimum of the 14 models (dashed green line) except for the alpine Jungfraujoch station. Overall, the average NMB and NME of all models and for all stations with available observations are $-34 \%$ and $78 \%$, respectively, while among individual models and stations NMB varies from about $-89 \%$ to about $253 \%$ (Table S6).

Comparing model performance for $\mathrm{CCN}$ at low supersaturation $\left(\mathrm{CCN}_{0.2} ;\right.$ Fig. 2$)$ and at high supersaturation $\left(\mathrm{CCN}_{1.0}\right.$; Fig. 4), $\mathrm{CCN}_{1.0}$ is systematically underestimated by the models across all stations. The NME of MMM for $\mathrm{CCN}_{0.2}$ ranges from $45 \%$ (Finokalia) to $81 \%$ (Jungfraujoch) for the different stations with significant correlation coefficients between 0.44 (Melpitz) and 0.86 (Mace Head), indicating that the MMM model is able to simulate the temporal variability 
in the observations. For $\mathrm{CCN}$ at the highest supersaturation with available observations the NME varies from $50 \%$ (Finokalia) to $74 \%$ (Mace Head) and the correlation coefficients from 0.37 (Melpitz) to 0.78 (Mace Head) (see also Table S6). These results indicate that $\mathrm{CCN}_{0.2}$ is in general better captured than $\mathrm{CCN}$ at higher supersaturations, both in absolute values and in temporal variability. Since the number concentration of CCN depends on both the chemical composition and the number of aerosol particles, it is worth investigating the role of these two factors separately.

\subsection{CCN number concentration comparisons with PPE}

$\mathrm{CCN}_{0.2}$ concentrations in perturbed parameter ensemble (PPE) simulations using HadGEM3-UKCA (Yoshioka et al., 2019) for 2008 at these stations are shown in Fig. 5, together with observations. The solid blue line shows the mean of the sample of 260000 model variants that cover the multidimensional uncertainty of the PPE (sampled using an emulator). The blue shading shows the range of 1 standard deviation around the mean, and the dotted lines show the minimum and maximum sampled values. The range of 1 standard deviation either side of the mean value represents approximately $68 \%$ of all samples, and therefore the blue shading shows approximately the same relative range as for the multi-model comparison in Fig. 2 (25\% and $75 \%$ quartiles). The MMM averaged for the years 2011-2015 is also plotted in this figure for comparison purposes together with the $25 \%$ and $75 \%$ quartile shaded area. The means of the available observations from the different years are shown by symbols. Since the interannual variability of simulated $\mathrm{MMM} \mathrm{CCN}_{0.2}$ concentrations shown in Fig. 2 is generally small compared to inter-model variability, the difference in years between simulations and observations is not considered to undermine the model-data comparisons.

Except for Mace Head, the uncertainty ranges in the PPE are somewhat smaller than the $25 \%$ and $75 \%$ quartiles of the models shown in Fig. 2. This suggests that model structural differences and the emission inventories used in different models are more important sources of diversity of estimated $\mathrm{CCN}_{0.2}$ concentrations for the central $70 \%$ range than the fully sampled parametric uncertainty in a single model. However, the maximum-minimum ranges are much larger in the PPE than in the MMM at many locations. Therefore, the values of the sampled model variants from the PPE are more concentrated near the mean but have longer tails on their distribution compared to values from MMM. This is to be expected from such a relatively small sample of models in the MMM.

Model-data comparisons are qualitatively similar to the case with MMM. The PPE simulations underestimate the observed $\mathrm{CCN}_{0.2}$ concentrations at many stations and in many months. Exceptions are Puy de Dôme and Hyytiälä where PPE simulations reproduce the observations well for most of the months and Finokalia where, just like MMM, the PPE
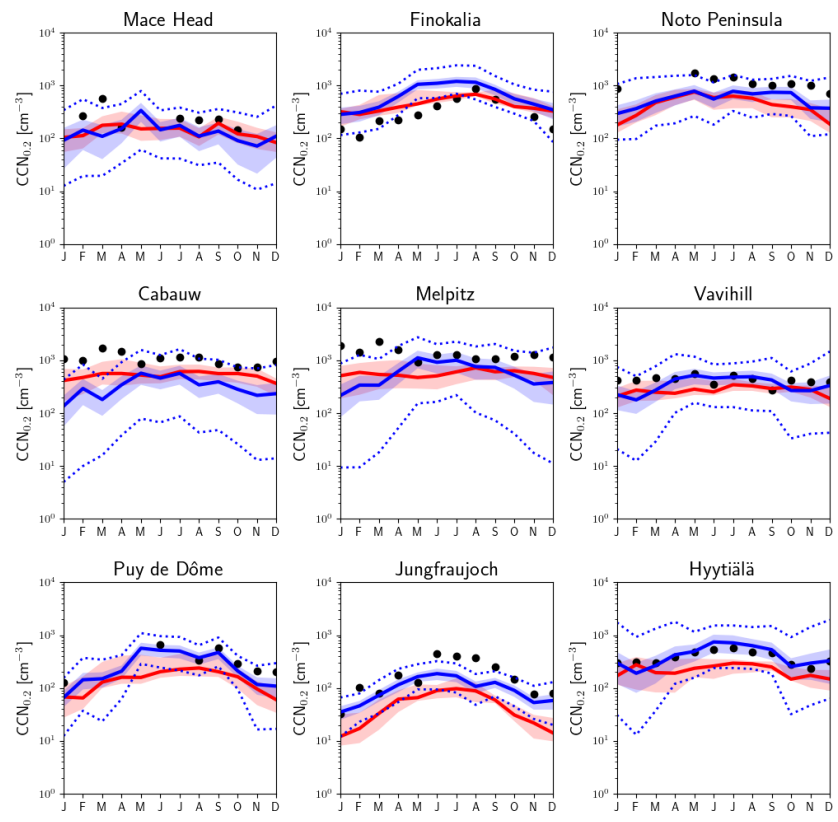

Figure 5. Monthly average $\mathrm{CCN}_{0.2}$ based on HadGEM3-UKCA perturbed parameter ensemble simulations for the year 2008. The solid blue line shows the mean of the sample of 260000 model variants from the emulator for each month and station. The shaded blue area shows the range of this mean plus and minus 1 standard deviation, while the blue dashed lines show the minimum and maximum sampled values. The red line shows the MMM results (mean of the years 2011-2015 shown in Fig. 2), and the shaded red area corresponds to the $25 \%$ and $75 \%$ quartiles. The $\mathrm{CCN}_{0.2}$ values obtained from observational data are shown by symbols (mean of the available data).

overestimates the observations. At Melpitz and Vavihill simulations capture the observed values in summer but underestimate them in winter and early spring. The PPE simulations fail to capture the observed peaks in winter and early spring at Mace Head and Cabauw as well. This is unlike the case with MMM, which does not show a distinct wintertime underestimate (Fig. 3). The qualitative agreement between PPE and MMM indicates that the perturbed parameters are those with significant control on aerosol processes and emissions and can be used for CCN uncertainty attribution in Sect. 5.

\subsection{Particle number concentration and $\mathrm{PM}_{1}$ aerosol chemical composition}

The observed critical diameter for particle activation into $\mathrm{CCN}$ at $0.2 \%$ supersaturation at most of the locations in this study is around $100 \mathrm{~nm}$ or larger, reaching about $200 \mathrm{~nm}$ in spring and summer at Finokalia (Schmale et al., 2018). Therefore, in Fig. 6, the MMMs of the simulated $\mathrm{N}_{50}$ and $\mathrm{N}_{120}$ are depicted together with the $25 \%$ and $75 \%$ quartiles of all models that provided station data and are compared with observations. $\mathrm{N}_{120}$ is expected to represent a significant portion of the activated particles at $0.2 \%$ or higher super- 

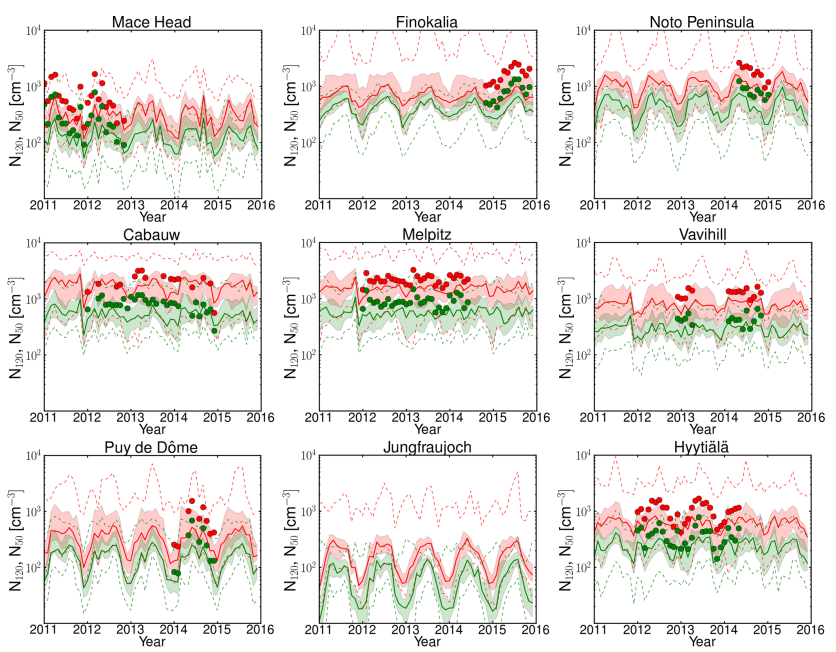

Figure 6. Monthly ensembles for the period 2011-2015 of the number concentration of particles with diameters larger than $50 \mathrm{~nm}\left(\mathrm{~N}_{50}\right.$ - in red) and $120 \mathrm{~nm}\left(\mathrm{~N}_{120}\right.$ - in green). The continuous lines correspond to the median of the models for each month; the shaded areas show the $25 \%$ and $75 \%$ quartiles and the dashed lines the minimum and maximum of all models for the $\mathrm{N}_{50}$ (red area) and $\mathrm{N}_{120}$ (green area). Observational data are available for all stations except Jungfraujoch and are shown with symbols of the corresponding color.

saturation. The MMM underestimates $\mathrm{N}_{50}$, and on average NMB is $-51 \%$ and NME is $55 \%$ for all stations. $\mathrm{N}_{80}$ is not shown in this figure but follows a similar behavior as $\mathrm{N}_{50}$ and $\mathrm{N}_{120}$. It is not surprising that in almost all cases both the $\mathrm{N}_{50}$ and the $\mathrm{N}_{120}$ concentrations are underestimated (the average NMB for MMM for all stations is $-50 \%$ and the NME is $54 \%$ ) by a factor that is only slightly lower than the underestimation of the $\mathrm{CCN}_{0.2}$ concentration $(-50 \% \mathrm{NMB}$ and $60 \% \mathrm{NME}$ ). It may therefore be concluded that the quantitative differences of the models in the prediction of CCN originate from the underestimation of the number concentration of aerosol particles in the relevant size ranges. Note, however, that the aerosol number concentration cannot be used as a proxy for $\mathrm{CCN}$ levels since activation of aerosols to $\mathrm{CCN}$ depends not only on the size distribution but also on the chemical composition of the aerosols as well as on the supersaturation that develops in clouds (e.g., Seinfeld and Pandis, 2006; Kalkavouras et al., 2019).

Figure S1 is similar to Figs. 2 and 4 but shows particulate $\mathrm{SO} 4, \mathrm{OA}$ mass in $\mathrm{PM}_{1}$ particles at the nine stations, and model results for DU and SS. Strong seasonal variations of the SO4 mass of about 1 order of magnitude are observed and simulated at the alpine site, Jungfraujoch, and at the coastal background stations, Mace Head and Finokalia, although winter minima are overestimated by the models at these coastal sites. Smaller variation or no clear seasonal variation of SO4 is observed at the boreal forest environment of Hyytiälä, the rural background station Cabauw and at the highly polluted Melpitz station during the year. At these three stations, the MMM underestimates the observed annual mean concentration of SO4. Strong seasonal variations of the OA mass are observed and simulated at Mace Head, Finokalia, Jungfraujoch and Hyytiälä, while no distinct seasonal cycle in organic mass is seen at Cabauw and Melpitz. The MMM is underestimating OA concentrations at all sites. The IoA between the MMM and the observations is between 0.28 and 0.62 for all stations. A detailed analysis of each model separately (Table S6) shows that the OA mass concentration is underestimated (mean NMB is $-37 \%$ ) by nine of the models and overestimated by six of them (range of NMB $-97 \%$ to $216 \%$ ). Because different models are appearing as outliers at each station, it is difficult to conclude whether the parameterizations in one model are better than another. This, however, is consistent with the findings of a recent OA intercomparison study that considered 31 models (Tsigaridis et al., 2014) and several modeling studies that suggest a missing source of OA needed to reconcile observations with model results (Spracklen et al., 2011; Heald et al., 2011). It appears therefore that in addition to the aerosol number concentration discussed earlier, a possible source of error in the simulation of aerosol and $\mathrm{CCN}$ number concentrations in the present study originates from the underestimation of the submicron OA mass at the stations where a significant contribution of the submicron OA mass to the $\mathrm{CCN}_{0.2}$ levels has been observed (Schmale et al., 2018). The importance of the contribution of OA to the uncertainty of $\mathrm{CCN}$ is also supported by the PPE simulations further discussed in Sect. 5.

\subsection{CCN persistence}

The above analysis of CCN and aerosol number concentrations shows that on average the models are able to simulate the seasonal variations in $\mathrm{CCN}$ concentrations, while the model-to-observation differences in the $\mathrm{CCN}$ concentrations can be attributed mainly to a systematic underestimation of the number of aerosol particles that are large enough to act as $\mathrm{CCN}$. The ability of models to simulate short-term variations (order of days) of the CCN number concentration is examined based on the calculated persistence of $\mathrm{CCN}_{0.2}$ number concentrations during summer and winter (see Sect. 2.4) for all stations and for each model. The average persistence times for all models are compared in Fig. 7 with those derived from the observations (Schmale et al., 2018). Depending on the season and the station, the persistence time varies from a few hours (e.g., summer in Mace Head) to several days (e.g., winter in Melpitz).

Depending on the station, the persistence time is longer during winter (five stations) than during summer (four stations). The average persistence of the $\mathrm{CCN}_{0.2}$ number concentrations simulated by the individual models is consistent with the observed change between winter and summer at six among the nine stations. At all stations, the simulations display a much smaller change from winter to summer than indi- 


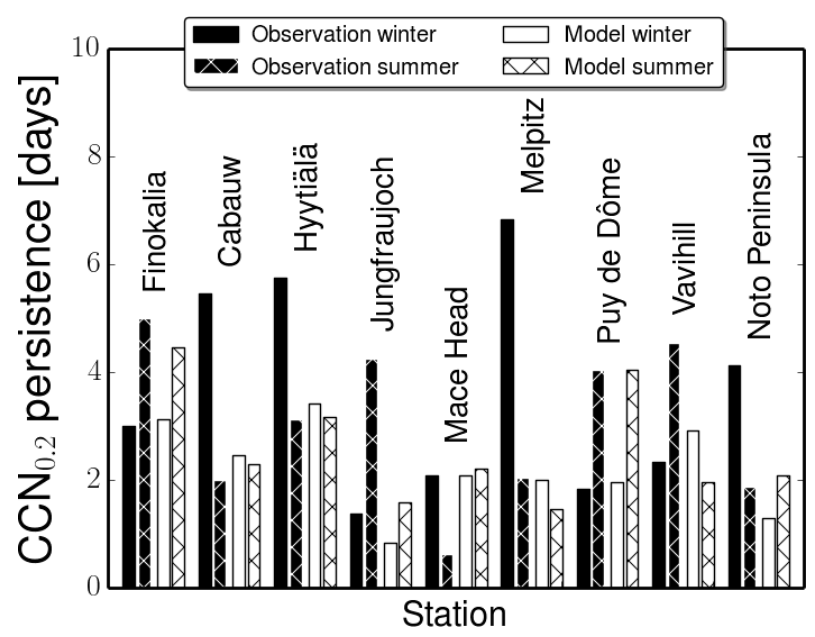

Figure 7. Comparison between the observed and the mean of the model-derived persistence (days) of $\mathrm{CCN}_{0.2}$ during winter (left bar) and summer (right shaded bar) for each station. The observed persistence times are shown in black for each station and the mean of the model-derived persistence times in white. The persistence times obtained from model simulations have been computed at the same time periods as the observed ones.

cated by the observations. Furthermore, the modeled change at Mace Head, the Noto Peninsula and Vavihill is opposite to the observed one. For the high-altitude stations, Puy de Dôme and Jungfraujoch, the models calculate longer persistence times during summer than during winter, in agreement with the observations. For these two high-altitude stations, a significant increase in the number concentration of $\mathrm{CCN}_{0.2}$ is observed during summer because the stations are subjected to the boundary layer air mass influence during that season, while during winter they are largely in the free troposphere. Therefore, despite the fact that the number concentration of $\mathrm{CCN}_{0.2}$ is overall underestimated, the models are able to reproduce the dynamical behavior of these continental background stations, most probably because they are able to simulate the local meteorological changes that drive CCN persistence (Fig. S4 and further discussion in Sect. S3.1).

Analyzing the factors that affect the persistence and then attributing the differences between the observed and the model-derived values to the underlying physical and/or chemical process parameterizations in each model is a demanding task, which is also likely to be model and case dependent. In addition to atmospheric transport patterns, dry and wet deposition processes are presumably affecting the persistence time. Because the present exercise was not focused on the deposition of aerosols, it does not have the necessary elements to elaborate on differences in the results associated with differences in the deposition parameterizations. However, earlier global model comparisons provide insight into such differences. The Tsigaridis et al. (2014) comparison of 31 global models, among which are those participat- ing in the present study, has shown that the representation of aerosol microphysics in the models was important for dry deposition. In particular, they have shown that the use of the M7 aerosol microphysics module was associated with low dry deposition fluxes of organic aerosol, which is mainly fine aerosol in the models, and the dry deposition rate coefficient ranged from 0.005 to $0.13 \mathrm{~d}^{-1}$, i.e., with a $\mathrm{max} / \mathrm{min}$ ratio of 26 . They also found that the effective wet deposition rate coefficient in the 31 participating models ranged from 0.09 to $0.24 \mathrm{~d}^{-1}$, i.e., with a $\mathrm{max} / \mathrm{min}$ ratio of 2.6 that is 10 times lower than for dry deposition, and found virtually no change between AEROCOM phase I and AEROCOM phase II models. Kim et al. (2014) compared the deposition of dust, which is mainly coarse aerosol, calculated by a smaller subset (five) of AEROCOM models. They pointed out that the size distribution of dust differs among these models and found a $30 \%$ difference in the effective dry deposition rate coefficient and about the same in the total deposition rate varying from 0.28 to $0.37 \mathrm{~d}^{-1}$. The Kim et al. (2014) analysis also revealed differences in the annual precipitation rate and in its seasonal distribution in the models, as well as factor of 2 differences in the fraction of wet to total deposition of dust among the models (ranging between 0.36 and 0.63 ). In addition, the PPE results (see Sect. 5) clearly show that dry deposition is one of the major factors of uncertainty in the calculations of CCN in $0.2 \%$ supersaturation. Kristiansen et al. (2016) investigated the causes of differences in aerosol lifetimes within 19 global models by making use of an observational constraint from radionuclide measurements and found largely underestimated accumulation-mode aerosol lifetimes due to removal in most models that is too fast. In particular, they found that the way aerosols are transported and scavenged in convective updrafts makes a large difference in aerosol vertical distribution and lifetimes, as revealed in their simulations from the same model (CAM5) but with different convective transport and wet removal treatments (Wang et al., 2013) .

Furthermore, the size of the emitted OA and BC particles has been shown to be an important parameter to which the persistence time and in particular the summer-to-winter ratio of the persistence time of $\mathrm{CCN}$ is sensitive (see sensitivity runs performed with one (TM4-ECPL) among the participating models in Sect. S3.1 and Fig. S5). Section 5 further attributes $\mathrm{CCN}_{0.2}$ uncertainty to various parameters.

\subsection{Cloud droplet number concentration from $\mathrm{CCN}$ spectra}

Inside a cloudy updraft, $s_{\max }$ is reached when supersaturation generation from expansion cooling becomes equal to its depletion by the condensation of water vapor onto the growing droplets (Nenes and Seinfeld, 2003). Increasing updraft velocity enhances the cooling rate of the cloudy air parcels, which in turn allows for higher supersaturation and eventually increases $s_{\max }$ and CDNC $\left(N_{\mathrm{d}}\right.$ in the following text and figures). Increases in $\mathrm{CCN}$ concentrations tend to increase $N_{\mathrm{d}}$ 
and associated water vapor depletion in the early stages of cloud formation; this in turn hinders the development of supersaturation and implies an eventual decrease in $s_{\max }$. This water vapor "competition effect" is especially strong when clouds form in the presence of large, hygroscopic particles such as sea-salt aerosol or large amounts of accumulation aerosol (Morales Betancourt and Nenes, 2014a; Ghan et al., 1998). Competition effects in turn explain why droplet number responses exhibit a sublinear response to modulations in $\mathrm{CCN}$; only when $\mathrm{CCN}$ concentrations are very low (or updraft velocities very high) does $s_{\max }$ become high enough so that the sensitivity of $N_{\mathrm{d}}$ to $\mathrm{CCN}$ approaches unity.

Based on the behavior described above, one can understand the $N_{\mathrm{d}}$ predicted from simulated and observed $\mathrm{CCN}$ spectra. This is straightforward for the Jungfraujoch and Mace Head stations. For Cabauw and Vavihill the observedto-simulated ratio turns from a substantial overestimation in $\mathrm{CCN}_{0.2}$ to an underestimation in $N_{\mathrm{d}}$, and the opposite is found for Finokalia. This can be explained as follows. At both Cabauw and Finokalia, $s_{\max }$ derived from observations is very low (approaching in the summer $0.07 \%$ at Finokalia and $0.04 \%$ at Cabauw; Fig. 8). The models overestimate these low values of $s_{\max }$, and such values are indicative of the presence of large particles $(>250 \mathrm{~nm}$ ) with sufficient hygroscopicity at these stations that are not captured by the models. Indeed, at Cabauw the available observations of $\mathrm{CCN}$ at $0.1 \%$ supersaturation show a larger underestimate by the models than for $\mathrm{CCN}_{1.0}$ and $\mathrm{CCN}_{0.2}$ (Fig. S16), also pointing to a model underestimate of the largest particles $(>250 \mathrm{~nm})$ that induce the very low $s_{\max }$. The overestimate in $s_{\max }$ leads to an underestimate in $N_{\mathrm{d}}$ by the models for all seasons except winter at Cabauw when the models at high updraft velocity capture the observationally derived $N_{\mathrm{d}}$ levels. Furthermore, at Finokalia, $\mathrm{CCN}_{1.0}$ is underestimated year-round, indicating that, in addition to the largest particles, the very small particles (smaller than $50 \mathrm{~nm}$ ) that activate at $1.0 \%$ supersaturation and/or their hygroscopicity are also underestimated by the models there. On the other hand, particles larger than $120 \mathrm{~nm}$ that activate at $0.2 \%$ supersaturation are overestimated, especially in winter, and slightly underestimated in summer. Therefore, the global models have significant difficulties in capturing the aerosol size distribution and hygroscopicity at Finokalia, which in turn translate into counterintuitive discrepancies in $N_{\mathrm{d}}$.

At Vavihill a somewhat different behavior is found; the underestimate of $\mathrm{CCN}$ at supersaturations of $0.2 \%$ and $0.7 \%$ changes to an overestimate at supersaturation $0.1 \%$ mainly in summer (Fig. S16), indicating an underestimate of fine particles and/or their hygroscopicity and an overestimate of the largest particles and/or their hygroscopicity, in particular during summer. This agreement of model results with observations during winter and the overestimate of $\mathrm{CCN}$ at $0.1 \%$ supersaturation during summer can explain the similar behavior of modeled $N_{\mathrm{d}}$.
The difference between model and observationally derived $\partial N_{\mathrm{d}} / \partial w$ clearly supports the above statements. Since observations predict a suppressed $s_{\max }$ compared to model distributions (Fig. 8), water vapor competition effects in the observations are much more severe than in the model, indicating that observations are much more (positively) sensitive to updraft velocity. The opposite trends are seen for activation fraction $\left(\partial N_{\mathrm{d}} / \partial N_{\mathrm{a}}\right)$, given that reductions in aerosol reduce competition effects. The reduced water vapor competition effects at higher updraft velocities and the trend in $\mathrm{CCN}$ error also generally explain why the sensitivities are smaller for the highest updraft velocity.

As expected, both $s_{\max }$ values and $N_{\mathrm{d}}$ for all observations and simulations are higher for $w=0.6 \mathrm{~ms}^{-1}$ than for $w=0.3 \mathrm{~ms}^{-1}$. The response of $s_{\max }$ and $N_{\mathrm{d}}$ to increasing $w$ also depends on the activated fraction (Fig. 8 third row). The calculated $N_{\mathrm{d}}$ increases progressively from the low values seen for the clean marine conditions at Mace Head and the high alpine atmospheric conditions of Jungfraujoch to the rural background conditions at Cabauw and Vavihill, while at Finokalia the observationally derived $N_{\mathrm{d}}$ values are the largest among the five stations (Fig. 9a). At Jungfraujoch, Finokalia and Mace Head, the seasonal variability of $N_{\mathrm{d}}$ is captured, despite the fact that the multi-model median tends to underestimate the observationally derived $N_{\mathrm{d}}$. However, the individual models show both overpredictions and underpredictions of the observations (Fig. S3). Owing to the water vapor competition effect, $s_{\max }$ decreases for increasing $N_{\mathrm{d}}$, meaning that clouds at a given location do not have a "characteristic $s_{\max }$ ", but rather depend on the given set of aerosol and dynamical conditions that develop during the cloud formation.

For all stations except Finokalia, the agreement between the model and observationally derived $N_{\mathrm{d}}$ (Fig. 8) tends to be better than for CCN (Figs. 2, 4) and aerosol number concentrations (Fig. 6) (as expressed by the MMM's NMB and NME for all stations provided in Table S6). Indeed, for all stations except Finokalia, NMB and NME of the MMM for $N_{\mathrm{d}}$ vary from $-7 \%$ to $-17 \%$ and $41 \%$ to $42 \%$, respectively, with the lowest values calculated for the low updraft velocity. For $\mathrm{CCN}_{0.2} \mathrm{NMB}$ is $-59 \%$ and NME $63 \%$, averaged over the same stations. This trend is a result of the competition effect of $\mathrm{CCN}$ on $s_{\max }$; if observed $\mathrm{CCN}$ concentrations are higher than predicted, then the "observed" $s_{\max }$ tends to be less than the "predicted" $s_{\max }$, which means the discrepancy in observed and predicted $N_{\mathrm{d}}$ is reduced compared to the CCN errors. The error reduction is substantial, especially under lower updraft velocity conditions. As a qualitative example we present here the ratio of the observed to the simulated average values of $\mathrm{CCN}_{0.2}$ number concentrations: 4.0 at Jungfraujoch, 2.2 at Cabauw, 2.1 at Mace Head, 1.5 at Vavihill and 0.8 at Finokalia (Fig. 3). In the case of $N_{\mathrm{d}}$ the corresponding ratios for $w=0.6 \mathrm{~m} \mathrm{~s}^{-1}$ are $\sim 1.8$ at Jungfraujoch, $\sim 0.9$ at Cabauw, $\sim 1.5$ at Mace Head, $\sim 0.9$ at Vavihill and $\sim 1.8$ at Finokalia (Fig. 9). All these ratios are inversely cor- 


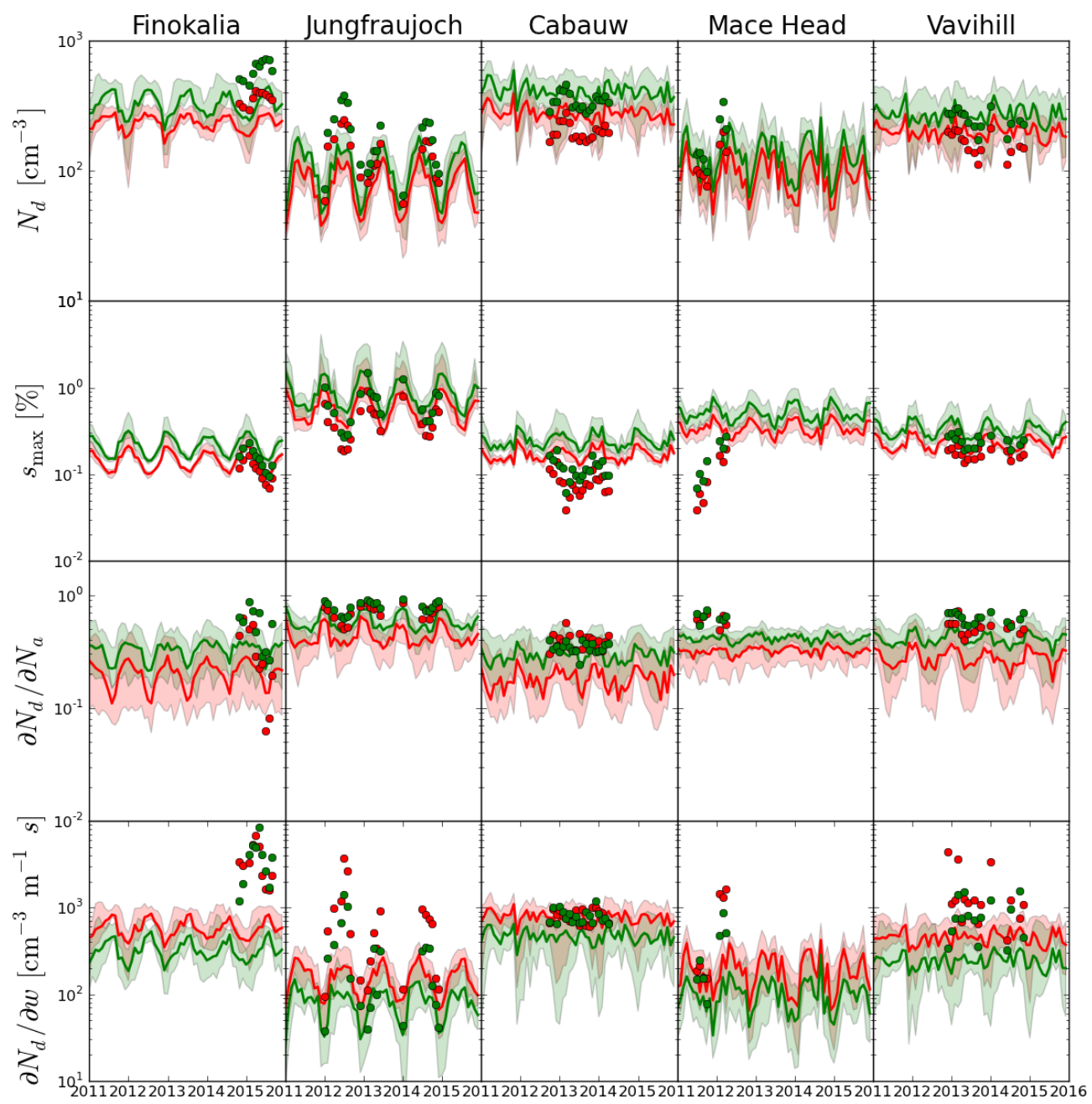

Figure 8. Comparison between the observed (symbols) and the monthly averages of all models (continuous lines) of the cloud droplet properties: in red for updraft velocity $w=0.3 \mathrm{~ms}^{-1}$ and in green for updraft velocity $w=0.6 \mathrm{~ms}^{-1}$. For each station from top to bottom the four graphs show (as indicated in the $y$ axis label) the number of cloud droplets, $N_{\mathrm{d}}$, the maximum supersaturation, $s_{\max }$, the sensitivity of the $N_{\mathrm{d}}$ to the total number of aerosol particles, $\left(\partial N_{\mathrm{d}} / \partial N_{\mathrm{a}}\right)$, and the sensitivity of the $N_{\mathrm{d}}$ to the updraft velocity $\left(\partial N_{\mathrm{d}} / \partial w\right)$.
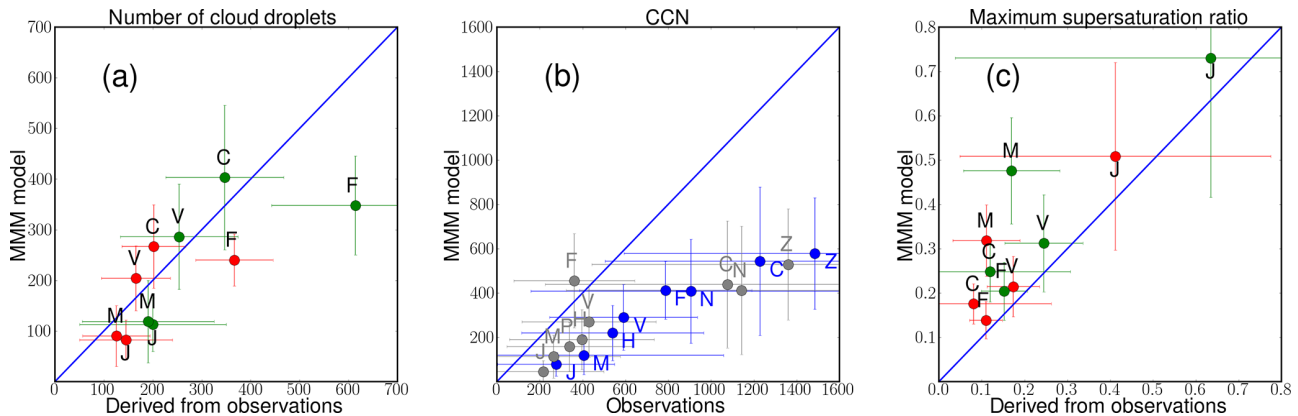

Figure 9. Scatter plot of the average of multi-model median results ( $y$ axis) versus observationally derived results ( $x$ axis) for (a) CDNC $\left(N_{\mathrm{d}}\right)\left(\mathrm{cm}^{-3}\right.$; in red for updraft velocity $w=0.3 \mathrm{~ms}^{-1}$ and in green for updraft velocity $\left.w=0.6 \mathrm{~ms}^{-1}\right)$; (b) CCN at supersaturation $0.2 \%$ (gray) and CCN at maximum supersaturation (blue) with available data $\left(\mathrm{cm}^{-3}\right)$. To fit the scale all CCN number concentrations at maximum supersaturation (blue symbols) have been divided by 2. Panel (c) is as panel (a) but for $s_{\max }(\%)$. The letters close to the symbols indicate the station names (C - Cabauw, F - Finokalia, H - Hyytiälä, J - Jungfraujoch, M - Mace Head, N - Noto Peninsula, P - Puy de Dôme, V Vavihill, Z - Melpitz). 
related with the observed to the simulated average values of $s_{\max }$ (Fig. 9), a clear indication of competition effects on $N_{\mathrm{d}}$ and prediction error mitigation.

In agreement with our finding, Sotiropoulou et al. (2006) used a similar approach applied to observations from the ICARTT field campaign and estimated that a $20 \%-50 \%$ error in CCN closure results in a $10 \%-25 \%$ error in $N_{\mathrm{d}}$, while global simulations suggest global average $\mathrm{CCN}$ prediction error between $10 \%$ and $20 \%$ and a smaller corresponding $N_{\mathrm{d}}$ error between $7 \%$ and $14 \%$ (Sotiropoulou et al., 2007). Such a reduction in error can be explained by self-regulation by $N_{\mathrm{d}}$ since $s_{\max }$ decreases with increasing aerosol number concentration, as discussed by many studies published to date (e.g., Twomey et al., 1959; Charlson et al., 2001; Nenes and Seinfeld, 2003; Feingold and Siebert, 2009), giving rise to regions where $N_{\mathrm{d}}$ is relatively insensitive to changes in CCN or updraft velocity (e.g., Rissman et al., 2004; Reutter et al., 2017). At very high CCN levels and in the presence of sufficiently large hygroscopic $\mathrm{CCN}, N_{\mathrm{d}}$ may actually decrease with increases in aerosol amount (Ghan and Abdul-Razzak, 1998; Feingold, 2001; McFiggans et al., 2006; Reutter et al., 2017); parameterizations that do not fully capture these important aspects of the aerosol-droplet relationship may also give rise to biases in aerosol indirect forcing assessments (e.g., Morales-Betancourt et al., 2014a).

These results clearly indicate that the number of $\mathrm{CCN}$ at a prescribed supersaturation cannot be used as an indicator for the number of activated droplets. The maximum supersaturation that develops inside the cloud (hence droplet number) responds to changes in aerosol and vertical velocity levels and is thus dynamically determined and can vary considerably for a given site. This is even further complicated by the potential for model biases to change sign at cloudrelevant supersaturations. $\mathrm{CCN}$-derived comparisons cannot even be used qualitatively, as the supersaturation levels can be so different from a prescribed value that even the error trend in $N_{\mathrm{d}}$ may not be reflected. For example, according to observationally derived data, $\mathrm{CCN}_{0.2}$ at Cabauw is significantly higher than at Finokalia, although at Finokalia $N_{\mathrm{d}}$ is larger for the observations but not for the model results. Our analysis, however, clearly shows that the models examined here do not exhibit the same level of $N_{\mathrm{d}}$ prediction error as $\mathrm{CCN}$ error $-\mathrm{a}$ robust trend that is a result of the physics of cloud droplet formation. Because of the discrepancy in the sensitivities $\partial N_{\mathrm{d}} / \partial N_{\mathrm{a}}$ and $\partial N_{\mathrm{d}} / \partial w$, models may be predisposed to be too "aerosol sensitive" or "aerosol insensitive" in aerosol-cloud-climate interaction studies, even if they may capture average droplet numbers well. This is a subtle but profound finding that only the sensitivities can clearly reveal and may explain inter-model biases on the aerosol indirect effect. Few published efforts (apart from Morales Betancourt and Nenes, 2014a, and Sullivan et al., 2016) can demonstrate this, none over a range of models and using a considerable aerosol dataset for evaluation as performed here.

\section{Global distributions of surface $\mathrm{CCN}_{0.2}$ and particle number concentrations}

The global near-surface annual mean MMM distributions of the $\mathrm{N}_{3}, \mathrm{~N}_{50}$ and $\mathrm{CCN}_{0.2}$ number concentrations for the year 2011 (Fig. 10) show similar patterns, i.e., larger concentrations over the continents due to the primary anthropogenic emissions over industrialized areas in the USA, Europe and Asia, as well as dust and biomass burning emissions in the tropics.

Multi-model median near-surface $\mathrm{N}_{3}$ number concentrations over continental regions vary between 1000 and $10600 \mathrm{~cm}^{-3}$, while over the marine boundary layer (MBL) they vary between 100 and $2000 \mathrm{~cm}^{-3}$, rarely exceeding $300 \mathrm{~cm}^{-3}$ (Fig. 10a). The MMM N $\mathrm{N}_{3}$ surface distribution is similar to the results by Spracklen et al. (2010) and Gordon et al. (2017), who computed maximum $\mathrm{N}_{3}$ concentrations of $\sim 10000 \mathrm{~cm}^{-3}$. The concentration of $\mathrm{N}_{3}$ is directly related to new particle formation and growth as well as to primary emitted particles. Since models use different nucleation mechanisms and emission inventories it is expected that the diversity of the model results is higher for $\mathrm{N}_{3}$ than for particle number concentrations with a larger (low-end) cutoff diameter. The largest diversities in the model results (Fig. 10b) are found in the polar regions, where concentrations are relatively low, and in the continental boundary layer with high values (about 2 ) observed in the tropics and particularly in South America and over the boreal regions in Asia. Diversities of up to 1.5 are computed for the Mediterranean, Arabian Peninsula, Central Africa, Indonesia and Southeast Asia, indicating differences between models in the representation of primary and secondary aerosol sources in these regions. Over the oceans the diversity is lower $(<1)$ except in the high latitudes of the Northern Hemisphere where it exceeds 1.5. Even lower model diversity (around 0.8 ) is found in highly polluted areas over North America and Europe, indicating consistency between models in the representation of aerosols in these regions. In addition to new particle formation, our results point mainly to biomass burning emissions as a major source of uncertainty in the model calculations, resulting in high model divergence in areas like southern Europe, tropical Africa and America, southern Asia and Indonesia. Assumption of emission injection height is also a source of discrepancy between models, leading to differences in the calculated lifetimes (up to $30 \%$ ) and in the tropospheric columns (up to $25 \%$ ) of pollutants (Daskalakis et al., 2015), while differences of an order of magnitude in their concentrations are computed for the middle troposphere (Jian and Fu, 2014). Thus, differences in the emission injection heights in the participating models, as outlined in Sect. 2.1 and Table S4, contribute to the model result divergence. The highest maximum $\mathrm{N}_{3}$ concentrations in a $5^{\circ} \times 5^{\circ}$ grid box (Fig. S6) were computed by the GISS-E2.1MATRIX model $\left(\sim 176000 \mathrm{~cm}^{-3}\right)$ and the TM4-ECPL model $\left(\sim 102000 \mathrm{~cm}^{-3}\right)$, while the lowest were from the 

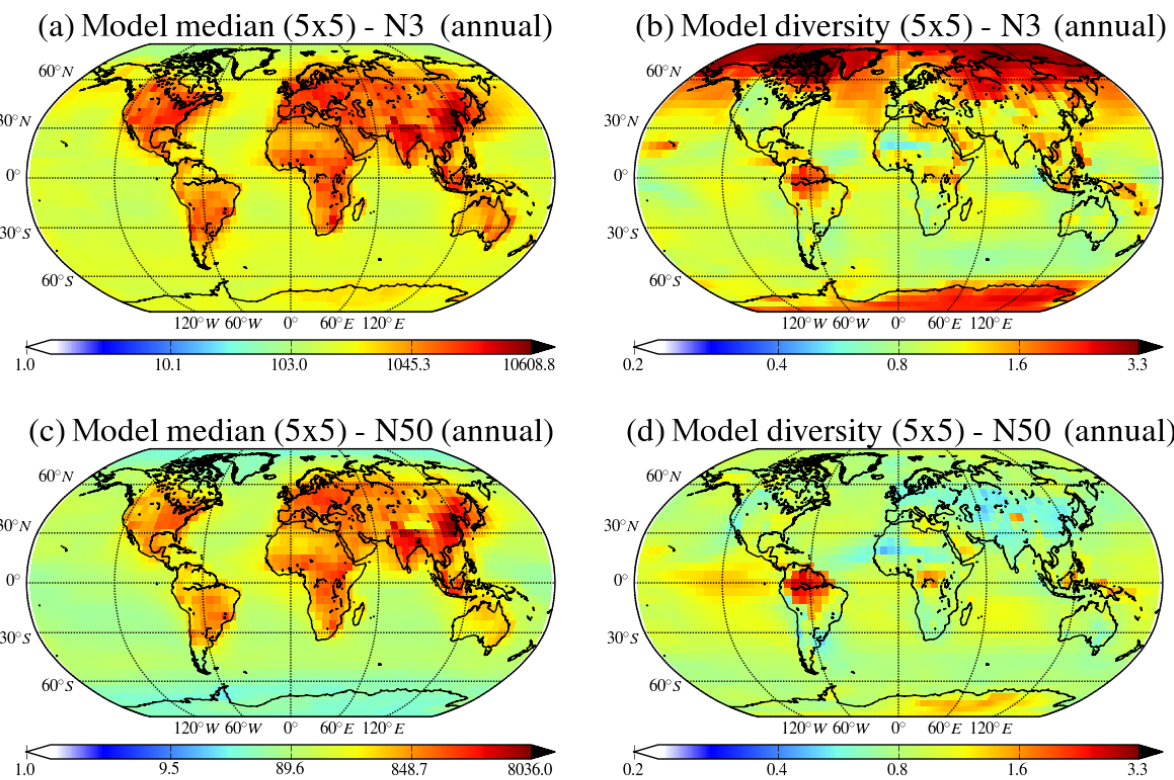

(d) Model diversity (5x5) - N50 (annual)

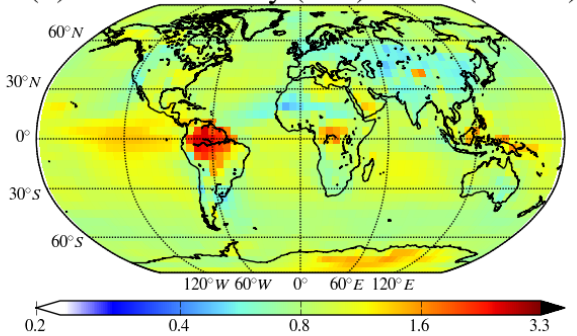

(e) Model median (5x5) - CCN (annual)

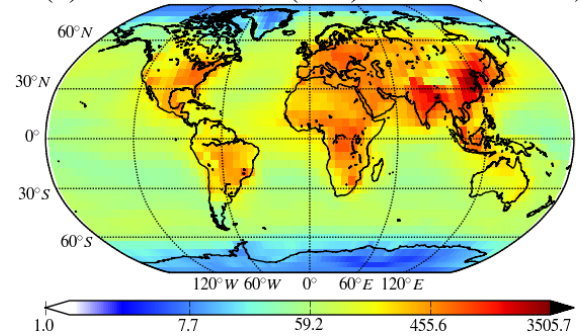

(f) Model diversity (5x5) - CCN (annual)

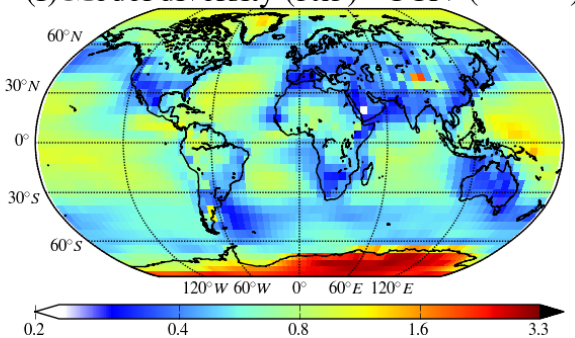

Figure 10. Global distributions of the annual multi-model median concentrations of $\mathrm{N}_{3}, \mathrm{~N}_{50}$ and $\mathrm{CCN}_{0.2}\left(\mathrm{~cm}^{-3}\right)$ for the year $2011(\mathbf{a}, \mathbf{c}$, e, respectively) and the corresponding diversities (b, d, f, respectively; calculated as the ratio of standard deviation to the mean of the models).

ECHAM6_HAM2-AP model $\left(\sim 6400 \mathrm{~cm}^{-3}\right)$. A sensitivity simulation was performed by a single model (TM4-ECPL; discussed in Sects. 3.3 and S3.1 and Fig. S5) assuming the same primary emissions of carbonaceous aerosol in terms of mass to be emitted at larger particle sizes. This additional simulation shows the importance of the assumptions on size distribution of the emissions in the models since the results of this simulation are very close to the average of the other models. In agreement with these findings, Spracklen et al. (2010) concluded that the sensitivity of $\mathrm{N}_{3}$ to the size of emitted particles originating from anthropogenic activities is significantly higher in regions close to anthropogenic sources and significantly lower at remote boundary layer sites.

The annual global mean distribution of near-surface $\mathrm{N}_{50}$ particle number concentrations (Fig. 10c) is similar to that of the $\mathrm{N}_{3}$ particles, but the number concentrations are lower for these larger particle sizes that are more relevant for $\mathrm{CCN}$. The spatial distributions of $\mathrm{N}_{50}$ are similar, but their concentrations are reduced by about a factor of 2.5 compared to $\mathrm{N}_{3}$. The highest values of $\mathrm{N}_{50}$ are found over or close to industrialized regions due to anthropogenic emissions and over Central Africa and South America due to strong biomass burning emissions. Over marine regions, $\mathrm{N}_{50}$ is higher in the Northern Hemisphere than in the Southern Hemisphere due to the outflow from continental anthropogenic sources. Despite the similarities of the global MMM distributions, the models' diversity and spatial pattern of $\mathrm{N}_{50}$ (Fig. 10d) differ significantly from that of $\mathrm{N}_{3}$. Excluding polar regions as for $\mathrm{N}_{3}$, the highest model diversities for $\mathrm{N}_{50}(\sim 2)$ are observed in regions with strong biomass burning emissions (southern America, Central Africa and Indonesia), and high diversities are also found over the tropical Pacific, which might be associated with marine emission representation in the models. In all other regions the diversity of $\mathrm{N}_{50}$ simulations does not exceed 1 , even over the remaining tropical and southern oceans where sea salt is important.

The near-surface MMM concentrations of $\mathrm{CCN}_{0.2}$ do not exceed $3500 \mathrm{~cm}^{-3}$ over polluted areas in Europe, Asia and the United States, as shown in Fig. 10e. This value is in the range of the $3162-10000 \mathrm{~cm}^{-3} \mathrm{CCN}_{0.2}$ concentrations simulated by Spracklen et al. (2011) over China and attributed to carbonaceous aerosols acting as $\mathrm{CCN}$. In the present study, only one model (EMAC) computes $\mathrm{CCN}_{0.2}$ levels that exceed $10000 \mathrm{~cm}^{-3}$ over the Taklimakan Desert 
in Asia, while the remaining 14 models show maximum surface $\mathrm{CCN}_{0.2}$ concentrations $<5000 \mathrm{~cm}^{-3}$ (see Fig. S9). The surface distribution and magnitude of $\mathrm{CCN}_{0.2}$ are similar to $\mathrm{N}_{120}$ (Fig. S8), with the maximum $\mathrm{CCN}_{0.2}$ concentrations only slightly lower than the $\mathrm{N}_{120}$ values for most models, indicating that most of the $\mathrm{N}_{120}$ particles activate, implying a global mean kappa of $\sim 0.2$ for $120 \mathrm{~nm}$ particles. However, analysis of the individual model results over the polluted areas shows that the number concentration of $\mathrm{N}_{120}$ can, in most cases, be either $50 \%$ lower or higher than that of $\mathrm{CCN}_{0.2}$. The modeled $\mathrm{CCN}_{0.2}$ diversity is lower than the diversity for $\mathrm{N}_{50}$ with values $<0.5$ for midlatitude continental regions and around 1 over the tropical oceans, where the $\mathrm{CCN}_{0.2}$ number concentration is usually lower than $60 \mathrm{~cm}^{-3}$, but also over tropical southern Africa and Central Africa where $\mathrm{CCN}_{0.2}$ number concentration is a few hundred cubic centimeters. $\mathrm{CCN}_{0.2}$ model diversity is also lower than that of $\mathrm{N}_{3}$ simulations. The maximum reduction of the model diversity in $\mathrm{CCN}_{0.2}$ simulations compared to that in $\mathrm{N}_{3}$ simulations is found to exceed a factor of 9 and maximizes over the high latitudes of the Northern Hemisphere and the south Arabian Peninsula where new particle formation is high. Overall, a global mean reduction of a factor of about 2 is found, as shown in Fig. S18, that provides the ratio of $\mathrm{N}_{3}$ model diversity (Fig. 10b) over $\mathrm{CCN}_{0.2}$ model diversity (Fig. 10f).

Some of the differences in global near-surface distributions of CCN (Fig. S9) can be associated with the corresponding differences in the computed $\mathrm{SO} 4$ and $\mathrm{OA}$ surface distributions (Figs. S10 and S11, respectively). For instance, in China and South America, models that are biased low in $\mathrm{SO} 4$ and high in OA are also biased low in CCN. Significant differences are also found for black carbon, sea salt and dust $\mathrm{PM}_{1}$ components (Figs. S12-S14). In particular, for all models near-surface $\mathrm{BC}$ distributions maximize over China, while individual models differ by a factor of 3 to 4 . Simulated SS distributions maximize over the southern oceans where the models show the largest differences of up to 2 orders of magnitude, reflecting large differences in the parameterized emissions of SS (see also Table S3). Finally, DU distributions show the largest spread among models with near-surface values that differ by up to a factor of 40 . The global surface distributions of the MMM of the chemical compound ( $\mathrm{SO} 4$, $\mathrm{BC}, \mathrm{OA}, \mathrm{SS}$ and DU) concentrations that contribute to $\mathrm{PM}_{1}$ are shown in Fig. S15 (left column) together with the corresponding model diversities (right column). For all simulated $\mathrm{PM}_{1}$ components diversities maximize south of $60^{\circ} \mathrm{S}$ and north of $60^{\circ} \mathrm{N}$, similarly to $\mathrm{N}_{3}$, which reflects the challenges of the models in simulating atmospheric transport, deposition and chemistry close to the poles.

\section{Causes of uncertainty in $\mathrm{CCN}$}

In this section we use the HadGEM-UKCA perturbed parameter ensemble (PPE) to identify some potential causes of model diversity and bias compared to the observations. We performed a variance-based sensitivity analysis at each measurement site using the 260000 HadGEM-UKCA model variants sampled from the emulator following the methodology described in previous studies (Lee et al., 2013; Johnson et al., 2018).

Figure 11 shows the fraction of variance in $\mathrm{CCN}_{0.2}$ that can be attributed to each of the perturbed parameters. Here we draw attention to the main parameter effects and refer to Yoshioka et al. (2019) for a full description of all parameters. The list of these parameters is provided in the caption of Fig. 11. In the summer, the largest contributions to uncertainty in $\mathrm{CCN}_{0.2}$ at most sites come from the biogenic volatile organic compound (BVOC) emission flux and the assumed hygroscopicity of the organic matter in the particles $\left(\kappa_{\mathrm{OA}}\right)$. The BVOC emissions in this model are assumed to be $\alpha$-pinene and to have an uncertainty range of $12-225 \mathrm{Tg}$ SOA production per year. The $\kappa_{\mathrm{OA}}$ is assumed to have a range of $0.1-0.6$ and to be fixed during the simulation time (i.e., the hygroscopicity does not change due to within-particle oxidation). Together, these two mostly biogenic-related parameters account for up to $90 \%$ of the CCN variance in summer, ranging from about $0 \%$ at Mace Head, $20 \%$ at Cabauw, $40 \%$ at Finokalia and $70 \%$ at Melpitz to $90 \%$ at Hyytiälä. These results show that at Hyytiälä the organic fraction of $\mathrm{CCN}$-active aerosol is highest, while at other locations, like Mace Head, the inorganic fraction dominates the total hygroscopicity. Except at the Mace Head coastal site, the other important parameters in summer are dry deposition of aerosol, anthropogenic $\mathrm{SO}_{2}$ emissions (at Finokalia, Puy de Dôme and Jungfraujoch), the fossil fuel emission flux (at the Noto Peninsula, Cabauw and Melpitz) and the assumed width of the accumulation mode (at Jungfraujoch and Puy de Dôme).

In winter, aerosol dry deposition is an important cause of uncertainty in $\mathrm{CCN}_{0.2}$ at all sites except Jungfraujoch and Puy de Dôme. At most sites (except Mace Head and the Noto Peninsula) the emissions fluxes (and the assumed particle sizes) of carbonaceous aerosol from fossil fuel and residential combustion sources account for $10 \%-20 \%$ of the uncertainty. Aging of aerosol through the uptake of sulfuric acid and SOA is also important at these sites. Finally, the production of sulfate through in-cloud oxidation by ozone (perturbed parameter marked as "Cloud $\mathrm{pH}$ ") accounts for $30 \%-40 \%$ of the uncertainty at Finokalia, Puy de Dôme and Jungfraujoch.

In summary, the PPE results suggest that the production of SOA from biogenic emissions combined with the hygroscopic properties of the OA should be investigated as a source of differences in predicted CCN between models in summer. In winter, dry deposition, aging and in-cloud sulfate production are the dominant sources of $\mathrm{CCN}$ uncertainty. Given that the importance of $\mathrm{CCN}$ prediction uncertainty may not always translate to CDNC uncertainty - especially if cloud formation occurs in a velocity-limited regime - any 

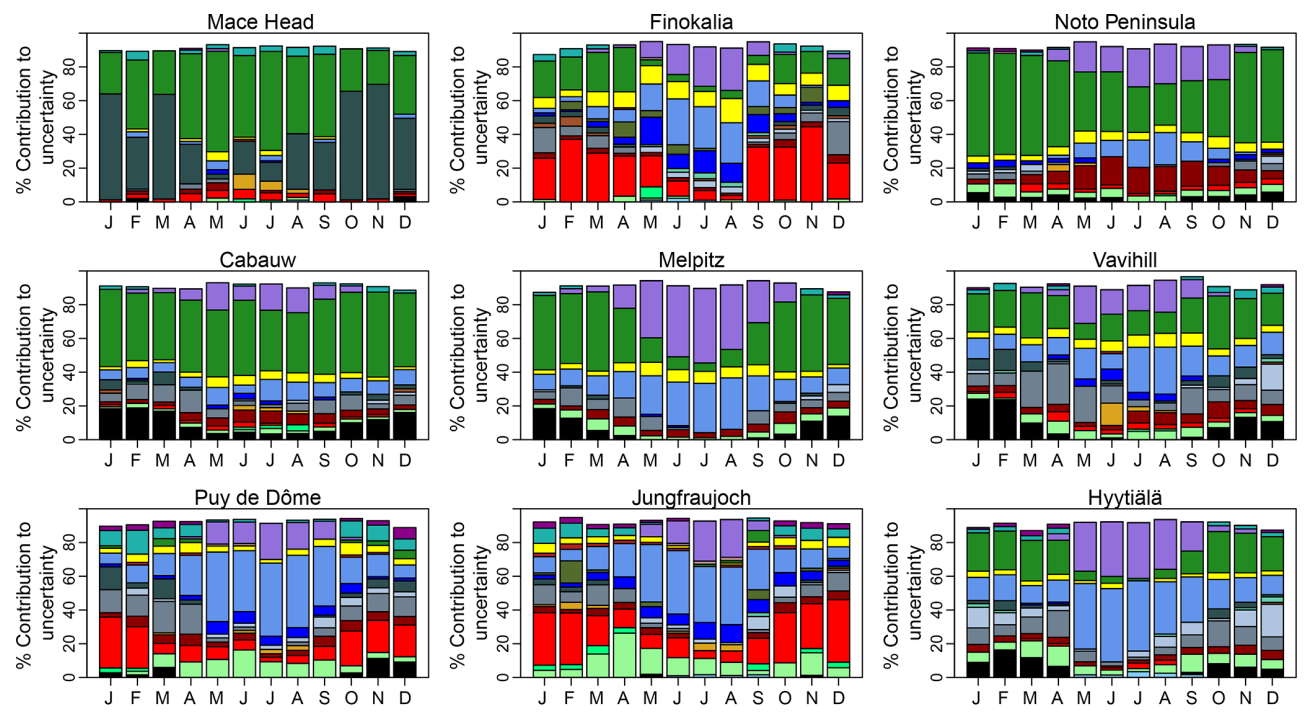

J F M A M J J A S O N

J F M A M J J A S O N D

口 BL_Nuc

- Aging

- Carb_BB_Ems

- Anth_SO2

口 Acc_Width

- Carb_Res_Ems

- Volc_SO2

- Carb_FF_Diam

口 Ait_Width

- Prim_SO4_Frac

- BVOC_SOA

- Dry_Dep_SO2

口 Sig_W

- Cloud_pH

- Prim_SO4_Diam

- DMS

Carb_FF_Ems

- Sea_Spray

- Dry_Dep_Ait

- Rain_Frac

- Cloud_Ice_Thresh

- Carb_BB_Diam

口 Carb_Res_Diam

Figure 11. Contribution to the uncertainty in monthly average $\mathrm{CCN}_{0.2}$ based on HadGEM3-UKCA perturbed parameter ensemble simulations for the year 2008. Each color refers to 1 of the 26 perturbed parameters as indicated in the legend of the figure. The uncertainty is shown as the percentage contribution of the parameter to the $\mathrm{CCN}_{0.2}$ variance. The assumed parameter uncertainty ranges are given in Yoshioka et al. (2019). All contributions smaller than $1 \%$ are not shown. Abbreviations are as follows. BL_Nuc: boundary layer nucleation; Aging: aging "rate" from insoluble to soluble; Acc_Width: modal width (accumulation soluble-insoluble); Ait_Width: modal width (Aitken soluble-insoluble); Cloud_pH: pH of cloud drops; Carb_FF_Ems: particle mass emission rate for BC and OC (fossil fuel); Carb_BB_Ems: particle mass emission rate for BC and OC (biomass burning); Carb_Res_Ems: particle mass emission rate for BC and OC (biofuel); Carb_FF_Diam: particle emitted mode diameter for BC and OC (fossil fuel); Carb_BB_Diam: particle emitted mode diameter for BC and OC (biomass burning); Carb_Res_Diam: particle emitted mode diameter for BC and OC (biofuel); Prim_SO4_Frac: mass fraction of $\mathrm{SO}_{2}$ converted to new $\mathrm{SO}_{4}^{-2}$ particles in sub-grid power plant plumes; Prim_SO4_Diam: mode diameter of new sub-grid $\mathrm{SO}_{4}^{-2}$ particles; Sea_Spray: sea spray mass flux (coarse / accumulation); Anth_SO2: $\mathrm{SO}_{2}$ emission flux (anthropogenic); $\mathrm{Volc} \_S O 2_{2} \mathrm{SO}_{2}$ emission flux (volcanic); BVOC_SOA: biogenic monoterpene production of SOA; DMS: DMS emission flux; Dry_Dep_Ait: dry deposition velocity of Aitken mode aerosol; Dry_Dep_Acc: dry deposition velocity of accumulation-mode aerosol; Dry_Dep_SO2: dry deposition velocity of $\mathrm{SO}_{2}$; Kappa_OC: hygroscopicity parameter kappa for organic aerosols. Default value in UKCA is 0.06; see Petters and Kreidenweis (2007). Sig_W: standard deviation of updraft velocity (this affects the activation of aerosol particles to form cloud droplets). Dust: dust emission flux; Rain_Frac: the fraction of the cloudy part of the grid box in which rain is forming and hence scavenging takes place; Cloud_Ice_Thresh: scavenging (by both cloud liquid and ice water) is suppressed in dynamic clouds when cloud ice fraction is higher than this value. The parameters with no color in the legend do not contribute to the uncertainty in $\mathrm{CCN}_{0.2}$ (less than $1 \%$ ) at any station in any month.

future analysis should place $\mathrm{CCN}$ uncertainty within the context of CDNC uncertainty.

\section{Summary and conclusions}

Within the BACCHUS-AEROCOM multi-model CCN intercomparison initiative, a total of 16 global aerosol-climate and chemistry transport models were compared to each other and to observations. Among them 14 provided results for particle and $\mathrm{CCN}$ number concentrations and $\mathrm{PM}_{1}$ component mass concentrations, which have been compared to surface observations at eight sites in Europe and one in Japan to evaluate the skill of the simulations.
In this inter-model comparison, models used different meteorology and emissions (e.g., CMIP5 and 6), as well as datasets and parameterizations. Most models (including the multi-model median) tend to underestimate the observed aerosol number concentrations $\mathrm{N}_{50}, \mathrm{~N}_{80}$ and $\mathrm{N}_{120}$, as well as the $\mathrm{CCN}$ concentrations, suggesting an incomplete understanding of the underlying processes. In particular, emissions and the size distribution of emitted particles, injection heights of biomass burning emissions, atmospheric aging and particularly aqueous-phase chemistry, the hygroscopicity of organic aerosol, and dry and wet deposition have been pointed out as main sources of uncertainties in model simulations. Models are, however, reproducing between $45 \%$ and $86 \%$ of the seasonal variability of $\mathrm{N}_{50}, \mathrm{~N}_{80}, \mathrm{~N}_{120}$ and 
$\mathrm{CCN}_{0.2}$ number concentrations, as well as $\mathrm{SO} 4$ and $\mathrm{OA}$ $\mathrm{PM}_{1}$ component mass concentrations, with the exception of Hyytiälä where only $36 \%$ of the SO4 variability is captured by the MMM, as indicated by the correlation coefficient of the MMM with the observations (Table S6). While models have improved since the 2014 AEROCOM organic aerosol intercomparison (Tsigaridis et al., 2014), most continue to underestimate the organic submicron aerosol mass concentrations. Thus, the MMM underestimates observed OA $\mathrm{PM}_{1}$ mass concentrations by $36 \%$ (for Hyytiälä) to $77 \%$ (for Jungfraujoch).

The simulated $\mathrm{N}_{3}$ number concentrations, which are generally higher over land, show high diversity among models over the Northern Hemisphere continents, while the simulated CCN are less diverse. Overall, a global mean reduction of a factor of about 2 is found in the model diversity in $\mathrm{CCN}_{0.2}$ simulations compared to that in $\mathrm{N}_{3}$ simulations, maximizing over regions where new particle formation is important. This finding points to differences in the size distribution of primary emissions and/or in the formation and growth of new particles as important sources of the inter-model diversity in $\mathrm{CCN}$.

$\mathrm{CCN}$ number concentrations are generally underestimated at all supersaturations by the MMM by at least $34 \%$ (Fig. 9, Table S6), with the exception of very low supersaturations, indicating that models have most difficulty in capturing the largest particles $(>250 \mathrm{~nm})$ that activate at very low supersaturations. There is no model that performs best at all stations. The models on average qualitatively capture the strong seasonal variabilities of CCN observed at Finokalia, the Noto Peninsula, Puy de Dôme and Jungfraujoch, as well as the very weak seasonality observed at the other stations. The production of SOA from biogenic emissions combined with the hygroscopic properties of the OA in summer and dry deposition, aging and in-cloud sulfate production in winter have been identified by PPE simulations as dominant sources of $\mathrm{CCN}$ uncertainty and should be investigated in the future.

The short-term variability of $\mathrm{CCN}_{0.2}$ at the measurement sites has been examined by comparing the $\mathrm{CCN}_{0.2}$ persistence time computed from the observed data and the model results. Because persistence time is a normalized timescale driven by the processes that "set" the CCN concentrations, it is more sensitive to air mass changes and the formationremoval rates of atmospheric particles than to the exact number concentration of CCN. With the exception of two models that estimate very large persistence times (about $16 \mathrm{~d}$ ) during summertime at Finokalia, the modeled persistence times of near-surface $\mathrm{CCN}_{0.2}$ are between 0.5 and $9 \mathrm{~d}$ depending on the model, location and season (Fig. S4), a range similar to that derived from observations that vary between about 0.5 and $7 \mathrm{~d}$. At six out of nine stations the average relative change in modeled persistence time between winter and summer is in agreement with observations. These persistence times of $\mathrm{CCN}_{0.2}$ are sensitive to assumptions on the size of the emit- ted particles, as shown by a sensitivity simulation with the TM4-ECPL model.

A novel aspect of this study is the comparison of ensemble global aerosol climate model near-surface results with experimentally derived CDNC from surface measurements of $\mathrm{CCN}$ at different levels of supersaturation. Note that CDNC is not calculated by each participating model, but a common methodology has been followed to derive the CDNC from the modeled and observed CCN spectra. Despite the large differences between models and observations found in the number concentration of aerosol particles and $\mathrm{CCN}$, the CDNC estimates based on the CCN spectra are in significantly better agreement than the $\mathrm{CCN}$ for the stations examined here. In addition, the inter-model spread of CDNC is smaller than that of particle and $\mathrm{CCN}$ number concentrations. These trends are robust and a result of the physics of cloud droplet response to aerosol perturbations and show self-regulation by CDNC.

As for $\mathrm{CCN}$ number concentrations, in several cases models underestimate CDNC when compared to the observationally derived CDNC (Sect. 3.5). At high aerosol number concentrations, the maximum supersaturation is computed to be low, limiting the fraction of particles that can activate and form CDNC. As a result, the sensitivity of CDNC to updraft velocity prevails. In contrast, at high updraft velocities, CDNC is controlled by the variability in the aerosol number concentration. An anticorrelation is found between the sensitivity of CDNC to the number of aerosols and that to the updraft velocity, showing that the variability of these two parameters can explain the variability in CDNC and limit CDNC formation.

Our results are in agreement with previous studies showing that CDNCs are sensitive to the uncertainties in the CCN number concentrations, mainly in regions where aerosol number concentrations are low and support the concept of the existence of two distinct regimes ("aerosol limited" and "updraft limited"). Unlike previous studies, however, we show that for a large number of models, persistent and substantial CCN prediction biases are considerably reduced when expressed as droplet number concentrations for boundarylayer-type clouds. Biases in CDNC are found to be qualitatively different from the biases in $\mathrm{CCN}_{0.2}$ and are attributed to the ability of models to capture the levels of the largest particles that activate at very low cloud-relevant supersaturations. These results point to the need for observations that cover the CCN spectra down to very low supersaturation levels and demonstrate that model-observation comparisons of $\mathrm{CCN}$ at a prescribed supersaturation may be misleading in the error evaluation for CDNC, since supersaturation is dynamically determined and can vary considerably for a given site. The methodology proposed here, however, overcomes this limitation and considers the dynamic nature of supersaturation adjustment to $\mathrm{CCN}$ variations, thus determining appropriate supersaturation levels for model-observation comparison. Such a methodology can help better guide modeling efforts to focus on regions where CDNC predictions are most 
biased and sensitive to $\mathrm{CCN}$ perturbations (e.g., in the southern oceans).

Data availability. The data used for this study are available online at https://doi.org/10.5281/zenodo.3265866 (Fanourgakis et al., 2019) (contact: Maria Kanakidou at mariak@uoc.gr). CDNC analysis tools for model and observational data can be obtained from athanasios.nenes@epfl.ch upon request.

Supplement. The supplement related to this article is available online at: https://doi.org/10.5194/acp-19-8591-2019-supplement.

Author contributions. GF performed TM4-ECPL model simulations, developed codes and drew all figures for the multi-model data analysis. MK initiated and coordinated the exercise. AN developed the codes to interpret the $\mathrm{CCN}$ spectra from all models and from the observations and to calculate CDNC. MK and AN defined the experimental protocol. GF, MK and AN analyzed data and wrote the paper. All coauthors contributed data and to the writing of the paper.

Competing interests. The authors declare that they have no conflict of interest.

Special issue statement. This article is part of the special issue "BACCHUS - Impact of Biogenic versus Anthropogenic emissions on Clouds and Climate: towards a Holistic UnderStanding (ACP/AMT/GMD inter-journal SI)"'. It is not associated with a conference.

Acknowledgements. This work has been initiated and conducted within the European Union's Seventh Framework Programme (FP7/2007-2013) collaborative project BACCHUS (Impact of Biogenic versus Anthropogenic emissions on Clouds and Climate: towards a Holistic UnderStanding). Dirk Olivie has contributed with coding and information about the emission heights used in CAM5.3-Oslo. Yunha Lee developed the GISS-E2-TOMAS model used in this study. The ECHAM-HAMMOZ model is developed by a consortium composed of ETH Zurich, the Max Planck Institut für Meteorologie, Forschungszentrum Jülich, the University of Oxford, the Finnish Meteorological Institute and the Leibniz Institute for Tropospheric Research; it is managed by the Center for Climate Systems Modeling (C2SM) at ETH Zurich. Hailong Wang and Yang Yang acknowledge support from the U.S. Department of Energy (DOE) Biological and Environmental Research and the ACTIVATE project (a NASA Earth Venture Suborbital-3 investigation) funded by NASA's Earth Science Division and managed through the Earth System Science Pathfinder Program Office. The Pacific Northwest National Laboratory (PNNL) is operated for the DOE by the Battelle Memorial Institute under contract DE-AC0576RLO1830. The CAM5_MAM3 simulation was performed using PNNL institutional computing resources. Resources supporting this work were also provided by the NASA High-End Computing (HEC) program through the NASA Center for Climate Simulation (NCCS) at Goddard Space Flight Center. Martin Gysel-Beer acknowledges support from MeteoSwiss in the framework of the Swiss contributions (GAW-CH and GAW-CH-Plus) to the Global Atmosphere Watch program of the World Meteorological Organization (WMO). This work was finalized when Maria Kanakidou was visiting L. Gallardo at the Center for Climate and Resilience Research (CR2) at the Geophysics Department of the University of Chile where Maria Kanakidou profited from fruitful discussions.

Financial support. This research has been supported by the FP7 Environment (grant no. BACCHUS (603445)), the H2020 Environment (grant nos. CRESCENDO (641816) and ACTRIS2 (654109)), and the H2020 European Research Council (grant nos. PyroTRACH (726165) and RECAP (724602)). The contributing authors were also supported by the following: the Norwegian Research Council (grant nos. 207711/E10, 229771, nn2345k and ns2345k); the Nordic Centre of Excellence eSTICC (grant no. 57001); the Natural Environment Research Council project (grant no. NE/L01355X/1); the Japan Society for the Promotion of Science, the Ministry of Education, Culture, Sports, Science, and Technology and the Japan Society for the Promotion of Science (grant nos. JP26740014, JP17H04709, JP26241003 and JP16H01770); the MEXT Green Network of Excellence and Arctic Challenge for Sustainability projects and the Environment Research and Technology Development Fund of the Environmental Restoration and Conservation Agency (grant nos. 2-1403, 2-1703); the U.S. National Science Foundation Atmospheric Chemistry Program (grant nos. AGS-1559607 and 1550816); the U.S. National Oceanic and Atmospheric Administration, an Office of Science, Office of Atmospheric Chemistry, Carbon Cycle, and Climate Program (grant no. NA17OAR430001); NASA (grant nos. NNX13AK20G and NNX15AE36G); the Swiss State Secretariat for Education, Research and Innovation (SERI) (grant no. 15.0159-1); and the Swiss National Supercomputing Centre (grant no. s652).

Review statement. This paper was edited by Joachim Curtius and reviewed by two anonymous referees.

\section{References}

Abdul Razzak, H. and Ghan, S. J.: A parameterization of aerosol activation: 2. Multiple aerosol types, J. Geophys. Res.-Atmos., 105, 6837-6844, https://doi.org/10.1029/1999JD901161, 2000.

Adams, P. J. and Seinfeld, J. H.: Predicting global aerosol size distributions in general circulation models, J. Geophys. Res.-Atmos., 107, 1-23, https://doi.org/10.1029/2001JD001010, 2002.

Barahona, D. and Nenes, A.: Parameterization of cloud droplet formation in large-scale models: Including effects of entrainment, J. Geophys. Res.-Atmos., 112, 1-14, https://doi.org/10.1029/2007JD008473, 2007.

Barahona, D., Molod, A., Bacmeister, J., Nenes, A., Gettelman, A., Morrison, H., Phillips, V., and Eichmann, A.: Development of two-moment cloud microphysics for liquid and ice within the NASA Goddard Earth Observing System Model (GEOS-5), 
Geosci. Model Dev., 7, 1733-1766, https://doi.org/10.5194/gmd7-1733-2014, 2014.

Bauer, S. E., Wright, D. L., Koch, D., Lewis, E. R., McGraw, R., Chang, L.-S., Schwartz, S. E., and Ruedy, R.: MATRIX (Multiconfiguration Aerosol TRacker of mIXing state): an aerosol microphysical module for global atmospheric models, Atmos. Chem. Phys., 8, 6003-6035, https://doi.org/10.5194/acp-8-60032008, 2008.

Bian, H., Chin, M., Hauglustaine, D. A., Schulz, M., Myhre, G., Bauer, S. E., Lund, M. T., Karydis, V. A., Kucsera, T. L., Pan, X., Pozzer, A., Skeie, R. B., Steenrod, S. D., Sudo, K., Tsigaridis, K., Tsimpidi, A. P., and Tsyro, S. G.: Investigation of global particulate nitrate from the AeroCom phase III experiment, Atmos. Chem. Phys., 17, 12911-12940, https://doi.org/10.5194/acp-1712911-2017, 2017

Boucher, O., Randall, D., Artaxo, P., Bretherton, C., Feingold, G., Forster, P., Kerminen, V.-M., Kondo, Y., Liao, H., Lohmann, U., Rasch, P., Satheesh, S. K., Sherwood, S., Stevens, B., and Zhang, X. Y.: Clouds and Aerosols, in: Climate Change 2013 - The Physical Science Basis, edited by: Intergovernmental Panel on Climate Change, 571-658, Cambridge University Press, Cambridge, 2013.

Bougiatioti, A., Fountoukis, C., Kalivitis, N., Pandis, S. N., Nenes, A., and Mihalopoulos, N.: Cloud condensation nuclei measurements in the marine boundary layer of the Eastern Mediterranean: CCN closure and droplet growth kinetics, Atmos. Chem. Phys., 9, 7053-7066, https://doi.org/10.5194/acp-9-7053-2009, 2009.

Bougiatioti, A., Nenes, A., Fountoukis, C., Kalivitis, N., Pandis, S. N., and Mihalopoulos, N.: Size-resolved CCN distributions and activation kinetics of aged continental and marine aerosol, Atmos. Chem. Phys., 11, 8791-8808, https://doi.org/10.5194/acp11-8791-2011, 2011.

Bougiatioti, A., Bezantakos, S., Stavroulas, I., Kalivitis, N., Kokkalis, P., Biskos, G., Mihalopoulos, N., Papayannis, A., and Nenes, A.: Biomass-burning impact on CCN number, hygroscopicity and cloud formation during summertime in the eastern Mediterranean, Atmos. Chem. Phys., 16, 7389-7409, https://doi.org/10.5194/acp-16-7389-2016, 2016.

Charlson, R. J., Seinfeld, J. H., Nenes, A., Kulmala, M., Laaksonen, A., and Facchini, M. C.: Reshaping the Theory of Cloud Formation, Science, 292, 2025-2026, 2001.

Cubison, M. J., Ervens, B., Feingold, G., Docherty, K. S., Ulbrich, I. M., Shields, L., Prather, K., Hering, S., and Jimenez, J. L.: The influence of chemical composition and mixing state of Los Angeles urban aerosol on CCN number and cloud properties, Atmos. Chem. Phys., 8, 5649-5667, https://doi.org/10.5194/acp-8-56492008, 2008.

D’Andrea, S. D., Häkkinen, S. A. K., Westervelt, D. M., Kuang, C., Levin, E. J. T., Kanawade, V. P., Leaitch, W. R., Spracklen, D. V., Riipinen, I., and Pierce, J. R.: Understanding global secondary organic aerosol amount and size-resolved condensational behavior, Atmos. Chem. Phys., 13, 11519-11534, https://doi.org/10.5194/acp-13-11519-2013, 2013.

D’Andrea, S. D., Ng, J. Y., Kodros, J. K., Atwood, S. A., Wheeler, M. J., Macdonald, A. M., Leaitch, W. R., and Pierce, J. R.: Source attribution of aerosol size distributions and model evaluation using Whistler Mountain measurements and GEOS-
Chem-TOMAS simulations, Atmos. Chem. Phys., 16, 383-396, https://doi.org/10.5194/acp-16-383-2016, 2016.

Daskalakis, N., Myriokefalitakis, S., and Kanakidou, M.: Sensitivity of tropospheric loads and lifetimes of short lived pollutants to fire emissions, Atmos. Chem. Phys., 15, 3543-3563, https://doi.org/10.5194/acp-15-3543-2015, 2015.

Deng, Z. Z., Zhao, C. S., Ma, N., Ran, L., Zhou, G. Q., Lu, D. R., and Zhou, X. J.: An examination of parameterizations for the $\mathrm{CCN}$ number concentration based on in situ measurements of aerosol activation properties in the North China Plain, Atmos. Chem. Phys., 13, 6227-6237, https://doi.org/10.5194/acp13-6227-2013, 2013.

Dentener, F., Kinne, S., Bond, T., Boucher, O., Cofala, J., Generoso, S., Ginoux, P., Gong, S., Hoelzemann, J. J., Ito, A., Marelli, L., Penner, J. E., Putaud, J.-P., Textor, C., Schulz, M., van der Werf, G. R., and Wilson, J.: Emissions of primary aerosol and precursor gases in the years 2000 and 1750 prescribed data-sets for AeroCom, Atmos. Chem. Phys., 6, 43214344, https://doi.org/10.5194/acp-6-4321-2006, 2006.

Dusek, U., Frank, G. P., Hildebrandt, L., Curtius, J., Schneider, J., Walter, S., Chand, D., Drewnick, F., Hings, S., Jung, D., Borrmann, S., and Andreae, M. O.: Size Matters More Than Chemistry Aerosol Particles, Science, 80, 1375-1378, https://doi.org/10.1126/science.1125261, 2006.

Ervens, B., Cubison, M., Andrews, E., Feingold, G., Ogren, J. A., Jimenez, J. L., DeCarlo, P., and Nenes, A.: Prediction of cloud condensation nucleus number concentration using measurements of aerosol size distributions and composition and light scattering enhancement due to humidity, J. Geophys. Res., 112, D10S32, https://doi.org/10.1029/2006JD007426, 2007.

Ervens, B., Cubison, M. J., Andrews, E., Feingold, G., Ogren, J. A., Jimenez, J. L., Quinn, P. K., Bates, T. S., Wang, J., Zhang, Q., Coe, H., Flynn, M., and Allan, J. D.: CCN predictions using simplified assumptions of organic aerosol composition and mixing state: a synthesis from six different locations, Atmos. Chem. Phys., 10, 4795-4807, https://doi.org/10.5194/acp10-4795-2010, 2010.

Fan, J., Wang, Y., Rosenfeld, D., Liu, X., Fan, J., Wang, Y., Rosenfeld, D., and Liu, X.: Review of Aerosol - Cloud Interactions: Mechanisms, Significance, and Challenges, J. Atmos. Sci., 73, 4221-4252, https://doi.org/10.1175/JAS-D-16-0037.1, 2016.

Fanourgakis, G., Kanakidou, M., Nenes, A., Bauer, S. E., Bergman, T., Carslaw, K. S., Grini, A., Hamilton, D. S., Johnson, J. S., Karydis, V. A., Kirkevåg, A., Kodros, J. K., Lohmann, U., Luo, G., Makkonen, R., Matsui, H., Neubauer, D., Pierce, J. R., Schmale, J., Stier, P., Tsigaridis, K., van Noije, T., Wang, H., Watson-Parris, D., Westervelt, D. M., Yang, Y., Yoshioka, M., Daskalakis, N., Decesari, S., Gysel-Beer, M., Kalivitis, N., Liu, X., Mahowald, N. M., Myriokefalitakis, S., Schrödner, R., Sfakianaki, M., Tsimpidi, A. P., Wu, M., and Yu, F.: Data for the "Evaluation of global simulations of aerosol particle and cloud condensation nuclei number, with implications for cloud droplet formation", Zenodo, Version v1, Data set, https://doi.org/10.5281/zenodo.3265866, 2019.

Feingold, G.: Analysis of smoke impact on clouds in Brazilian biomass burning regions: An extension of Twomey's approach, J. Geophys. Res., 106, 22907-22922, 2001.

Feingold, G. and Siebert, H.: Cloud-Aerosol Interactions from the Micro to the Cloud Scale, in: Clouds in the Perturbed Climate 
System: Their Relationship to Energy Balance, Atmospheric Dynamics, and Precipitation, edited by: Heintzenberg, J. and Charlson,, R. J., MIT Press, 2009.

Fountoukis, C. and Nenes, A.: Continued development of a cloud droplet formation parameterization for global climate models, J. Geophys. Res.-Atmos., 110, 1-10, https://doi.org/10.1029/2004JD005591, 2005.

Fountoukis, C. and Nenes, A.: ISORROPIA II: a computationally efficient thermodynamic equilibrium model for $\mathrm{K}^{+}-\mathrm{Ca}^{2+}-\mathrm{Mg}^{2+}-\mathrm{NH}_{4}^{+}-\mathrm{Na}^{+} \quad-\mathrm{SO}_{4}^{2-}-\mathrm{NO}_{3}^{-}-\mathrm{Cl}^{-}-\mathrm{H}_{2} \mathrm{O}$ aerosols, Atmos. Chem. Phys., 7, 4639-4659, https://doi.org/10.5194/acp-7-4639-2007, 2007.

Ghan, S. J., Gutzman, G. and Abdul-Razzak, H.: Competition between Sea Salt and Sulfate Particles as Cloud Condensation Nuclei, J. Atmos. Sci., 55, 3340-3347, 1998.

Gordon, H., Kirkby, J., Baltensperger, U., Bianchi, F., Breitenlechner, M., Curtius, J., Dias, A., Dommen, J., Donahue, N. M., Dunne, E. M., Duplissy, J., Ehrhart, S., Flagan, R. C., Frege, C., Fuchs, C., Hansel, A., Hoyle, C. R., Kulmala, M., Kürten, A., Lehtipalo, K., Makhmutov, V., Molteni, U., Rissanen, M. P., Stozkhov, Y., Tröstl, J., Tsagkogeorgas, G., Wagner, R., Williamson, C., Wimmer, D., Winkler, P. M., Yan, C., and Carslaw, K. S.: Causes and importance of new particle formation in the present-day and preindustrial atmospheres, J. Geophys. Res.-Atmos., 122, 8739-8760, https://doi.org/10.1002/2017JD026844, 2017.

Heald, C. L., Coe, H., Jimenez, J. L., Weber, R. J., Bahreini, R., Middlebrook, A. M., Russell, L. M., Jolleys, M., Fu, T.-M., Allan, J. D., Bower, K. N., Capes, G., Crosier, J., Morgan, W. T., Robinson, N. H., Williams, P. I., Cubison, M. J., DeCarlo, P. F., and Dunlea, E. J.: Exploring the vertical profile of atmospheric organic aerosol: comparing 17 aircraft field campaigns with a global model, Atmos. Chem. Phys., 11, 12673-12696, https://doi.org/10.5194/acp-11-12673-2011, 2011.

Herrmann, E., Weingartner, E., Henne, S., L., V., Bukowiecki, N., Steinbacher, M., Conen, F., Collaud Coen, M., Hammer, E., Jurányi, Z., Baltensperger, U., and Gysel, M.: Analysis of long-term aerosol size distribution data from Jungfraujoch with emphasis on free tropospheric conditions, cloud influence, and air mass transport. J. Geophys. Res., 120, 9459-9480, https://doi.org/10.1002/2015JD023660, 2015.

Huneeus, N., Schulz, M., Balkanski, Y., Griesfeller, J., Prospero, J., Kinne, S., Bauer, S., Boucher, O., Chin, M., Dentener, F., Diehl, T., Easter, R., Fillmore, D., Ghan, S., Ginoux, P., Grini, A., Horowitz, L., Koch, D., Krol, M. C., Landing, W., Liu, X., Mahowald, N., Miller, R., Morcrette, J.-J., Myhre, G., Penner, J., Perlwitz, J., Stier, P., Takemura, T., and Zender, C. S.: Global dust model intercomparison in AeroCom phase I, Atmos. Chem. Phys., 11, 7781-7816, https://doi.org/10.5194/acp11-7781-2011, 2011.

Iwamoto, Y., Kinouchi, K., Watanabe, K., Yamazaki, N., and Matsuki, A.: Simultaneous measurement of CCN activity and chemical composition of fine-mode aerosols at Noto peninsula, Japan, in autumn 2012, Aerosol Air Qual. Res., 16, 2107-2118, 2016.

Jian, Y. and Fu, T.-M.: Injection heights of springtime biomassburning plumes over peninsular Southeast Asia and their impacts on long-range pollutant transport, Atmos. Chem. Phys., 14, 3977-3989, https://doi.org/10.5194/acp-14-3977-2014, 2014.
Jimenez, J. L., Canagaratna, M. R., Donahue, N. M., Prevot, A. S. H., Zhang, Q., Kroll, J. H., DeCarlo, P. F., Allan, J. D., Coe, H., Ng, N. L., Aiken, A. C., Docherty, K. S., Ulbrich, I. M., Grieshop, A. P., Robinson, A. L., Duplissy, J., Smith, J. D., Wilson, K. R., Lanz, V. A., Hueglin, C., Sun, Y. L., Tian, J., Laaksonen, A., Raatikainen, T., Rautiainen, J., Vaattovaara, P., Ehn, M., Kulmala, M., Tomlinson, J. M., Collins, D. R., Cubison, M. J., Dunlea, E. J., Huffman, J. A., Onasch, T. B., Alfarra, M. R., Williams, P. I., Bower, K., Kondo, Y., Schneider, J., Drewnick, F., Borrmann, S., Weimer, S., Demerjian, K., Salcedo, D., Cottrell, L., Griffin, R., Takami, A., Miyoshi, T., Hatakeyama, S., Shimono, A., Sun, J. Y., Zhang, Y. M., Dzepina, K., Kimmel, J. R., Sueper, D., Jayne, J. T., Herndon, S. C., Trimborn, A. M., Williams, L. R., Wood, E. C., Middlebrook, A. M., Kolb, C. E., Baltensperger, U., and Worsnop, D. R.: Evolution of organic aerosols in the atmosphere, Science, 80, 1525-1529, https://doi.org/10.1126/science.1180353, 2009.

Johnson, J. S., Regayre, L. A., Yoshioka, M., Pringle, K. J., Lee, L. A., Sexton, D. M. H., Rostron, J. W., Booth, B. B. B., and Carslaw, K. S.: The importance of comprehensive parameter sampling and multiple observations for robust constraint of aerosol radiative forcing, Atmos. Chem. Phys., 18, 1303113053, https://doi.org/10.5194/acp-18-13031-2018, 2018.

Jurányi, Z., Gysel, M., Weingartner, E., Bukowiecki, N., Kammermann, L., and Baltensperger, U.: A 17 month climatology of the cloud condensation nuclei number concentration at the high alpine site Jungfraujoch, J. Geophys. Res., 116, D10204, https://doi.org/10.1029/2010JD015199, 2011.

Kalivitis, N., Kerminen, V.-M., Kouvarakis, G., Stavroulas, I., Bougiatioti, A., Nenes, A., Manninen, H. E., Petäjä, T., Kulmala, M., and Mihalopoulos, N.: Atmospheric new particle formation as a source of $\mathrm{CCN}$ in the eastern Mediterranean marine boundary layer, Atmos. Chem. Phys., 15, 9203-9215, https://doi.org/10.5194/acp-15-9203-2015, 2015.

Kalkavouras, P., Bougiatioti, A., Kalivitis, N., Stavroulas, I., Tombrou, M., Nenes, A., and Mihalopoulos, N.: Regional new particle formation as modulators of cloud condensation nuclei and cloud droplet number in the eastern Mediterranean, Atmos. Chem. Phys., 19, 6185-6203, https://doi.org/10.5194/acp19-6185-2019, 2019.

Kanakidou, M., Seinfeld, J. H., Pandis, S. N., Barnes, I., Dentener, F. J., Facchini, M. C., Van Dingenen, R., Ervens, B., Nenes, A., Nielsen, C. J., Swietlicki, E., Putaud, J. P., Balkanski, Y., Fuzzi, S., Horth, J., Moortgat, G. K., Winterhalter, R., Myhre, C. E. L., Tsigaridis, K., Vignati, E., Stephanou, E. G., and Wilson, J.: Organic aerosol and global climate modelling: a review, Atmos. Chem. Phys., 5, 1053-1123, https://doi.org/10.5194/acp-5-10532005, 2005.

Karydis, V. A., Capps, S. L., Russell, A. G., and Nenes, A.: Adjoint sensitivity of global cloud droplet number to aerosol and dynamical parameters, Atmos. Chem. Phys., 12, 9041-9055, https://doi.org/10.5194/acp-12-9041-2012, 2012.

Kerminen, V.-M., Petäjä, T., Manninen, H. E., Paasonen, P., Nieminen, T., Sipilä, M., Junninen, H., Ehn, M., Gagné, S., Laakso, L., Riipinen, I., Vehkamäki, H., Kurten, T., Ortega, I. K., Dal Maso, M., Brus, D., Hyvärinen, A., Lihavainen, H., Leppä, J., Lehtinen, K. E. J., Mirme, A., Mirme, S., Hõrrak, U., Berndt, T., Stratmann, F., Birmili, W., Wiedensohler, A., Metzger, A., Dommen, J., Baltensperger, U., Kiendler-Scharr, A., Mentel, T. 
F., Wildt, J., Winkler, P. M., Wagner, P. E., Petzold, A., Minikin, A., Plass-Dülmer, C., Pöschl, U., Laaksonen, A., and Kulmala, M.: Atmospheric nucleation: highlights of the EUCAARI project and future directions, Atmos. Chem. Phys., 10, 10829-10848, https://doi.org/10.5194/acp-10-10829-2010, 2010.

Kerminen, V.-M., Paramonov, M., Anttila, T., Riipinen, I., Fountoukis, C., Korhonen, H., Asmi, E., Laakso, L., Lihavainen, H., Swietlicki, E., Svenningsson, B., Asmi, A., Pandis, S. N., Kulmala, M., and Petäjä, T.: Cloud condensation nuclei production associated with atmospheric nucleation: a synthesis based on existing literature and new results, Atmos. Chem. Phys., 12, 1203712059, https://doi.org/10.5194/acp-12-12037-2012, 2012.

Kim, D., Chin, M., Yu, H., Diehl, T., Tan, Q., Kahn, R. A., Tsigaridis, K., Bauer, S. E., Takemura, T., Pozzoli, L., Bellouin, N., Schulz, M., Peyridieu, S., Chédin, A., and Koffi, B.: Sources, sinks, and transatlantic transport of North African dust aerosol: A multimodel analysis and comparison with remote sensing data, J. Geophys. Res.-Atmos., 119, 6259-6277, https://doi.org/10.1002/2013JD021099. 2014.

Kirkevåg, A., Grini, A., Olivié, D., Seland, Ø., Alterskjær, K., Hummel, M., Karset, I. H. H., Lewinschal, A., Liu, X., Makkonen, R., Bethke, I., Griesfeller, J., Schulz, M., and Iversen, T.: A production-tagged aerosol module for Earth system models, OsloAero5.3 - extensions and updates for CAM5.3-Oslo, Geosci. Model Dev., 11, 3945-3982, https://doi.org/10.5194/gmd-11-3945-2018, 2018.

Köhler, H.: The nucleus in and the growth of hygroscopic droplets, Trans. Faraday Soc., 32, 1152-1161, https://doi.org/10.1039/TF9363201152, 1936.

Kristiansen, N. I., Stohl, A., Olivié, D. J. L., Croft, B., Søvde, O. A., Klein, H., Christoudias, T., Kunkel, D., Leadbetter, S. J., Lee, Y. H., Zhang, K., Tsigaridis, K., Bergman, T., Evangeliou, N., Wang, H., Ma, P.-L., Easter, R. C., Rasch, P. J., Liu, X., Pitari, G., Di Genova, G., Zhao, S. Y., Balkanski, Y., Bauer, S. E., Faluvegi, G. S., Kokkola, H., Martin, R. V., Pierce, J. R., Schulz, M., Shindell, D., Tost, H., and Zhang, H.: Evaluation of observed and modelled aerosol lifetimes using radioactive tracers of opportunity and an ensemble of 19 global models, Atmos. Chem. Phys., 16, 3525-3561, https://doi.org/10.5194/acp16-3525-2016, 2016.

Kulmala, M. and Kerminen, V. M.: On the formation and growth of atmospheric nanoparticles, Atmos. Res., 90, 132-150, https://doi.org/10.1016/j.atmosres.2008.01.005, 2008.

Kulmala, M., Laaksonen, A., and Pirjola, L.: Parameterizations for sulfuric acid/water nucleation rates, J. Geophys. Res., 103, 8301, https://doi.org/10.1029/97JD03718, 1998.

Laaksonen, A., Kulmala, M., O’Dowd, C. D., Joutsensaari, J., Vaattovaara, P., Mikkonen, S., Lehtinen, K. E. J., Sogacheva, L., Dal Maso, M., Aalto, P., Petäjä, T., Sogachev, A., Yoon, Y. J., Lihavainen, H., Nilsson, D., Facchini, M. C., Cavalli, F., Fuzzi, S., Hoffmann, T., Arnold, F., Hanke, M., Sellegri, K., Umann, B., Junkermann, W., Coe, H., Allan, J. D., Alfarra, M. R., Worsnop, D. R., Riekkola, M.-L., Hyötyläinen, T., and Viisanen, Y.: The role of VOC oxidation products in continental new particle formation, Atmos. Chem. Phys., 8, 2657-2665, https://doi.org/10.5194/acp-8-2657-2008, 2008.

Lee, L. A., Pringle, K. J., Reddington, C. L., Mann, G. W., Stier, P., Spracklen, D. V., Pierce, J. R., and Carslaw, K. S.: The magnitude and causes of uncertainty in global model simulations of cloud condensation nuclei, Atmos. Chem. Phys., 13, 8879-8914, https://doi.org/10.5194/acp-13-8879-2013, 2013.

Lee, Y. H., Adams, P. J., and Shindell, D. T.: Evaluation of the global aerosol microphysical ModelE2-TOMAS model against satellite and ground-based observations, Geosci. Model Dev., 8, 631-667, https://doi.org/10.5194/gmd-8-631-2015, 2015.

Liu, X., Easter, R. C., Ghan, S. J., Zaveri, R., Rasch, P., Shi, X., Lamarque, J.-F., Gettelman, A., Morrison, H., Vitt, F., Conley, A., Park, S., Neale, R., Hannay, C., Ekman, A. M. L., Hess, P., Mahowald, N., Collins, W., Iacono, M. J., Bretherton, C. S., Flanner, M. G., and Mitchell, D.: Toward a minimal representation of aerosols in climate models: description and evaluation in the Community Atmosphere Model CAM5, Geosci. Model Dev., 5, 709-739, https://doi.org/10.5194/gmd-5-709-2012, 2012.

Liu, X., Ma, P.-L., Wang, H., Tilmes, S., Singh, B., Easter, R. C., Ghan, S. J., and Rasch, P. J.: Description and evaluation of a new four-mode version of the Modal Aerosol Module (MAM4) within version 5.3 of the Community Atmosphere Model, Geosci. Model Dev., 9, 505-522, https://doi.org/10.5194/gmd-9505-2016, 2016.

Makkonen, R., Asmi, A., Korhonen, H., Kokkola, H., Järvenoja, S., Räisänen, P., Lehtinen, K. E. J., Laaksonen, A., Kerminen, V.M., Järvinen, H., Lohmann, U., Bennartz, R., Feichter, J., and Kulmala, M.: Sensitivity of aerosol concentrations and cloud properties to nucleation and secondary organic distribution in ECHAM5-HAM global circulation model, Atmos. Chem. Phys. 9, 1747-1766, https://doi.org/10.5194/acp-9-1747-2009, 2009.

Mann, G. W., Carslaw, K. S., Ridley, D. A., Spracklen, D. V., Pringle, K. J., Merikanto, J., Korhonen, H., Schwarz, J. P., Lee, L. A., Manktelow, P. T., Woodhouse, M. T., Schmidt, A., Breider, T. J., Emmerson, K. M., Reddington, C. L., Chipperfield, M. P., and Pickering, S. J.: Intercomparison of modal and sectional aerosol microphysics representations within the same 3-D global chemical transport model, Atmos. Chem. Phys., 12, 4449-4476, https://doi.org/10.5194/acp-12-4449-2012, 2012.

Matsui, H.: Development of a global aerosol model using a two-dimensional sectional method?: 1, Model design, J. Adv. Model. Earth Syst., 9, 1921-1947, https://doi.org/10.1002/2017MS000936, 2017.

McFiggans, G., Artaxo, P., Baltensperger, U., Coe, H., Facchini, M. C., Feingold, G., Fuzzi, S., Gysel, M., Laaksonen, A., Lohmann, U., Mentel, T. F., Murphy, D. M., O’Dowd, C. D., Snider, J. R., and Weingartner, E.: The effect of physical and chemical aerosol properties on warm cloud droplet activation, Atmos. Chem. Phys., 6, 2593-2649, https://doi.org/10.5194/acp-6-25932006, 2006.

Metzger, S., Dentener, F., Pandis, S., and Lelieveld, J.: Gas/aerosol partitioning: 1. A computationally efficient model, J. Geophys. Res.-Atmos., 107, 16-1-24, https://doi.org/10.1029/2001JD001102, 2002a.

Metzger, S., Dentener, F., Krol, M., Jeuken, A., and Lelieveld, J.: Gas/aerosol partitioning 2. Global modeling results, J. Geophys. Res.-Atmos., 107, 1-23, https://doi.org/10.1029/2001JD001103, 2002b.

Moore, R. H., Karydis, V. A., Capps, S. L., Lathem, T. L., and Nenes, A.: Droplet number uncertainties associated with CCN: an assessment using observations and a global model adjoint, Atmos. Chem. Phys., 13, 4235-4251, https://doi.org/10.5194/acp13-4235-2013, 2013. 
Morales Betancourt, R. and Nenes, A.: Characteristic updrafts for computing distribution-averaged cloud droplet number and stratocumulus cloud properties, J. Geophys. Res.-Atmos., 115, 2-9, https://doi.org/10.1029/2009JD013233, 2010.

Morales Betancourt, R. and Nenes, A.: Understanding the contributions of aerosol properties and parameterization discrepancies to droplet number variability in a global climate model, Atmos. Chem. Phys., 14, 4809-4826, https://doi.org/10.5194/acp14-4809-2014, 2014a.

Morales Betancourt, R. and Nenes, A.: Droplet activation parameterization: the population-splitting concept revisited, Geosci. Model Dev., 7, 2345-2357, https://doi.org/10.5194/gmd-7-23452014, 2014b.

Myhre, G., Samset, B. H., Schulz, M., Balkanski, Y., Bauer, S., Berntsen, T. K., Bian, H., Bellouin, N., Chin, M., Diehl, T., Easter, R. C., Feichter, J., Ghan, S. J., Hauglustaine, D., Iversen, T., Kinne, S., Kirkevåg, A., Lamarque, J.-F., Lin, G., Liu, X., Lund, M. T., Luo, G., Ma, X., van Noije, T., Penner, J. E., Rasch, P. J., Ruiz, A., Seland, Ø., Skeie, R. B., Stier, P., Takemura, T., Tsigaridis, K., Wang, P., Wang, Z., Xu, L., Yu, H., Yu, F., Yoon, J.-H., Zhang, K., Zhang, H., and Zhou, C.: Radiative forcing of the direct aerosol effect from AeroCom Phase II simulations, Atmos. Chem. Phys., 13, 1853-1877, https://doi.org/10.5194/acp13-1853-2013, 2013.

Myriokefalitakis, S., Nenes, A., Baker, A. R., Mihalopoulos, N., and Kanakidou, M.: Bioavailable atmospheric phosphorous supply to the global ocean: a 3-D global modeling study, Biogeosciences, 13, 6519-6543, https://doi.org/10.5194/bg-13-6519-2016, 2016.

Nenes, A. and Seinfeld, J. H.: Parameterization of cloud droplet formation in global climate models, J. Geophys. Res.-Atmos., 108, 4415, https://doi.org/10.1029/2002JD002911, 2003.

Ovadnevaite, J., Ceburnis, D., Leinert, S., Dall'Osto, M., Canagaratna, M., O'Doherty, S., Berresheim, H., and O'Dowd, C.: Submicron NE Atlantic marine aerosol chemical composition and abundance: Seasonal trends and air mass categorization, J. Geophys. Res.-Atmos., 119, 11850-11863, https://doi.org/10.1002/2013JD021330, 2014.

Petters, M. D. and Kreidenweis, S. M.: A single parameter representation of hygroscopic growth and cloud condensation nucleus activity, Atmos. Chem. Phys., 7, 1961-1971, https://doi.org/10.5194/acp-7-1961-2007, 2007.

Pierce, J. R., Riipinen, I., Kulmala, M., Ehn, M., Petäjä, T., Junninen, H., Worsnop, D. R., and Donahue, N. M.: Quantification of the volatility of secondary organic compounds in ultrafine particles during nucleation events, Atmos. Chem. Phys., 11, 90199036, https://doi.org/10.5194/acp-11-9019-2011, 2011.

Pringle, K. J., Tost, H., Pozzer, A., Pöschl, U., and Lelieveld, J.: Global distribution of the effective aerosol hygroscopicity parameter for CCN activation, Atmos. Chem. Phys., 10, 52415255, https://doi.org/10.5194/acp-10-5241-2010, 2010.

Pruppacher, H. R. and Klett, J. D.: Microphysics of clouds and precipitation, 2nd ed., Kluwer Academic Publishers, Dordrecht, The Netherlands, 1997.

Reutter, P., Su, H., Trentmann, J., Simmel, M., Rose, D., Gunthe, S. S., Wernli, H., Andreae, M. O., and Pöschl, U.: Aerosol- and updraft-limited regimes of cloud droplet formation: influence of particle number, size and hygroscopicity on the activation of cloud condensation nuclei (CCN), Atmos. Chem. Phys., 9, 70677080, https://doi.org/10.5194/acp-9-7067-2009, 2009.
Riccobono, F., Schobesberger, S., Scott, C. E., Dommen, J., Ortega, I. K., Rondo, L., Almeida, J., Amorim, A., Bianchi, F., Breitenlechner, M., David, A., Downard, A., Dunne, E. M., Duplissy, J., Ehrhart, S., Flagan, R. C., Franchin, A., Hansel, A., Junninen, H., Kajos, M., Keskinen, H., Kupc, A., Kürten, A., Kvashin, A. N., Laaksonen, A., Lehtipalo, K., Makhmutov, V., Mathot, S., Nieminen, T., Onnela, A., Petäjä, T., Praplan, A. P., Santos, F. D., Schallhart, S., Seinfeld, J. H., Sipilä, M., Spracklen, D. V, Stozhkov, Y., Stratmann, F., Tomé, A., Tsagkogeorgas, G., Vaattovaara, P., Viisanen, Y., Vrtala, A., Wagner, P. E., Weingartner, E., Wex, H., Wimmer, D., Carslaw, K. S., Curtius, J., Donahue, N. M., Kirkby, J., Kulmala, M., Worsnop, D. R., and Baltensperger, U.: Oxidation Products of Biogenic Emissions Contribute to Nucleation of Atmospheric Particles, Science, 80, 717 721, 2014.

Rissman, T., Nenes, A., and Seinfeld, J. H.: Chemical amplification (or dampening) of the Twomey effect: Conditions derived from droplet activation theory, J. Atmos. Sci., 61, 919-930, 2004.

Schmale, J., Henning, S., Henzing, B., Keskinen, H., Sellegri, K., Ovadnevaite, J., Bougiatioti, A., Kalivitis, N., Stavroulas, I., Jefferson, A., Park, M., Schlag, P., Kristensson, A., Iwamoto, Y., Pringle, K., Reddington, C., Aalto, P., Äijälä, M., Baltensperger, U., Bialek, J., Birmili, W., Bukowiecki, N., Ehn, M., Fjæraa, A. M., Fiebig, M., Frank, G., Fröhlich, R., Frumau, A., Furuya, M., Hammer, E., Heikkinen, L., Herrmann, E., Holzinger, R., Hyono, H., Kanakidou, M., Kiendler-Scharr, A., Kinouchi, K., Kos, G., Kulmala, M., Mihalopoulos, N., Motos, G., Nenes, A., O’Dowd, C., Paramonov, M., Petäjä, T., Picard, D., Poulain, L., Prévôt, A. S. H., Slowik, J., Sonntag, A., Swietlicki, E., Svenningsson, B., Tsurumaru, H., Wiedensohler, A., Wittbom, C., Ogren, J. A., Matsuki, A., Yum, S. S., Myhre, C. L., Carslaw, K., Stratmann, F., and Gysel, M.: Collocated observations of cloud condensation nuclei, particle size distributions, and chemical composition, Sci. Data, 4, 170003, https://doi.org/10.1038/sdata.2017.3, 2017.

Schmale, J., Henning, S., Decesari, S., Henzing, B., Keskinen, H., Sellegri, K., Ovadnevaite, J., Pöhlker, M. L., Brito, J., Bougiatioti, A., Kristensson, A., Kalivitis, N., Stavroulas, I., Carbone, S., Jefferson, A., Park, M., Schlag, P., Iwamoto, Y., Aalto, P., Äijälä, M., Bukowiecki, N., Ehn, M., Frank, G., Fröhlich, R., Frumau, A., Herrmann, E., Herrmann, H., Holzinger, R., Kos, G., Kulmala, M., Mihalopoulos, N., Nenes, A., O’Dowd, C., Petäjä, T., Picard, D., Pöhlker, C., Pöschl, U., Poulain, L., Prévôt, A. S. H., Swietlicki, E., Andreae, M. O., Artaxo, P., Wiedensohler, A., Ogren, J., Matsuki, A., Yum, S. S., Stratmann, F., Baltensperger, U., and Gysel, M.: Long-term cloud condensation nuclei number concentration, particle number size distribution and chemical composition measurements at regionally representative observatories, Atmos. Chem. Phys., 18, 2853-2881, https://doi.org/10.5194/acp-18-2853-2018, 2018.

Schutgens, N. A. J., Gryspeerdt, E., Weigum, N., Tsyro, S., Goto, D., Schulz, M., and Stier, P.: Will a perfect model agree with perfect observations? The impact of spatial sampling, Atmos. Chem. Phys., 16, 6335-6353, https://doi.org/10.5194/acp-166335-2016, 2016.

Seinfeld, J. and Pandis, S.: Atmospheric Chemistry and Physics: From Air Pollution to Climate Change, J. Wiley, New York, 2006.

Seinfeld, J. H., Bretherton, C., Carslaw, K. S., Coe, H., DeMott, P. J., Dunlea, E. J., Feingold, G., Ghan, S., Guenther, A. B., 
Kahn, R., Kraucunas, I., Kreidenweis, S. M., Molina, M. J., Nenes, A., Penner, J. E., Prather, K. A., Ramanathan, V., Ramaswamy, V., Rasch, P. J., Ravishankara, A. R., Rosenfeld, D., Stephens, G., and Wood, R.: Improving our fundamental understanding of the role of aerosol-cloud interactions in the climate system, P. Natl. Acad. Sci. USA, 113, 5781-5790, https://doi.org/10.1073/pnas.1514043113, 2016.

Sotiropoulou, R.-E. P., Medina, J., and Nenes, A.: CCN predictions: Is theory sufficient for assessments of the indirect effect?, Geophys. Res. Lett., 33, L05816, https://doi.org/10.1029/2005GL025148, 2006.

Sotiropoulou, R. E. P., Nenes, A., Adams, P. J., and Seinfeld, J. H.: Cloud condensation nuclei prediction error from application of Köhler theory: Importance for the aerosol indirect effect, J. Geophys. Res.-Atmos., 112, D12202, https://doi.org/10.1029/2006JD007834, 2007.

Spracklen, D. V., Bonn, B., and Carslaw, K. S.: Boreal forests, aerosols and the impacts on clouds and climate, Philos. Trans. A. Math. Phys. Eng. Sci., 366, 4613-26, https://doi.org/10.1098/rsta.2008.0201, 2008.

Spracklen, D. V., Carslaw, K. S., Pöschl, U., Rap, A., and Forster, P. M.: Global cloud condensation nuclei influenced by carbonaceous combustion aerosol, Atmos. Chem. Phys., 11, 9067-9087, https://doi.org/10.5194/acp-11-9067-2011, 2011.

Spracklen, D. V., Carslaw, K. S., Merikanto, J., Mann, G. W., Reddington, C. L., Pickering, S., Ogren, J. A., Andrews, E., Baltensperger, U., Weingartner, E., Boy, M., Kulmala, M., Laakso, L., Lihavainen, H., Kivekäs, N., Komppula, M., Mihalopoulos, N., Kouvarakis, G., Jennings, S. G., O’Dowd, C., Birmili, W., Wiedensohler, A., Weller, R., Gras, J., Laj, P., Sellegri, K., Bonn, B., Krejci, R., Laaksonen, A., Hamed, A., Minikin, A., Harrison, R. M., Talbot, R., and Sun, J.: Explaining global surface aerosol number concentrations in terms of primary emissions and particle formation, Atmos. Chem. Phys., 10, 4775-4793, https://doi.org/10.5194/acp-10-4775-2010, 2010.

Sullivan, R. C., Moore, M. J. K., Petters, M. D., Kreidenweis, S. M., Roberts, G. C., and Prather, K. A.: Effect of chemical mixing state on the hygroscopicity and cloud nucleation properties of calcium mineral dust particles, Atmos. Chem. Phys., 9, 33033316, https://doi.org/10.5194/acp-9-3303-2009, 2009.

Sullivan, S. C., Lee, D., Oreopoulos, L., and Nenes, A.: Role of updraft velocity in temporal variability of global cloud hydrometeor number, P. Natl. Acad. Sci. USA, 113, 5791-5796, https://doi.org/10.1073/pnas.1514039113, 2016.

Tegen, I., Neubauer, D., Ferrachat, S., Siegenthaler-Le Drian, C., Bey, I., Schutgens, N., Stier, P., Watson-Parris, D., Stanelle, T., Schmidt, H., Rast, S., Kokkola, H., Schultz, M., Schroeder, S., Daskalakis, N., Barthel, S., Heinold, B., and Lohmann, U.: The global aerosol-climate model ECHAM6.3-HAM2.3 - Part 1: Aerosol evaluation, Geosci. Model Dev., 12, 1643-1677, https://doi.org/10.5194/gmd-12-1643-2019, 2019.

Textor, C., Schulz, M., Guibert, S., Kinne, S., Balkanski, Y., Bauer, S., Berntsen, T., Berglen, T., Boucher, O., Chin, M., Dentener, F., Diehl, T., Easter, R., Feichter, H., Fillmore, D., Ghan, S., Ginoux, P., Gong, S., Grini, A., Hendricks, J., Horowitz, L., Huang, P., Isaksen, I., Iversen, I., Kloster, S., Koch, D., Kirkevåg, A., Kristjansson, J. E., Krol, M., Lauer, A., Lamarque, J. F., Liu, X., Montanaro, V., Myhre, G., Penner, J., Pitari, G., Reddy, S., Seland, Ø., Stier, P., Takemura, T., and Tie, X.: Analysis and quantification of the diversities of aerosol life cycles within AeroCom, Atmos. Chem. Phys., 6, 1777-1813, https://doi.org/10.5194/acp-6-17772006, 2006.

Tröstl, J., Chuang, W. K., Gordon, H., Heinritzi, M., Yan, C., Molteni, U., Ahlm, L., Frege, C., Bianchi, F., Wagner, R., Simon, M., Lehtipalo, K., Williamson, C., Craven, J. S., Duplissy, J., Adamov, A., Almeida, J., Bernhammer, A. K., Breitenlechner, M., Brilke, S., Dias, A., Ehrhart, S., Flagan, R. C., Franchin, A., Fuchs, C., Guida, R., Gysel, M., Hansel, A., Hoyle, C. R., Jokinen, T., Junninen, H., Kangasluoma, J., Keskinen, H., Kim, J., Krapf, M., Kürten, A., Laaksonen, A., Lawler, M., Leiminger, M., Mathot, S., Möhler, O., Nieminen, T., Onnela, A., Petäjä, T., Piel, F. M., Miettinen, P., Rissanen, M. P., Rondo, L., Sarnela, N., Schobesberger, S., Sengupta, K., Sipilä, M., Smith, J. N., Steiner, G., Tomè, A., Virtanen, A., Wagner, A. C., Weingartner, E., Wimmer, D., Winkler, P. M., Ye, P., Carslaw, K. S., Curtius, J., Dommen, J., Kirkby, J., Kulmala, M., Riipinen, I., Worsnop, D. R., Donahue, N. M., and Baltensperger, U.: The role of low-volatility organic compounds in initial particle growth in the atmosphere, Nature, 533, 527-531, https://doi.org/10.1038/nature18271, 2016.

Tsigaridis, K., Koch, D., and Menon, S.: Uncertainties and importance of sea spray composition on aerosol direct and indirect effects, J. Geophys. Res.-Atmos., 118, 220-235, https://doi.org/10.1029/2012JD018165, 2013.

Tsigaridis, K., Daskalakis, N., Kanakidou, M., Adams, P. J., Artaxo, P., Bahadur, R., Balkanski, Y., Bauer, S. E., Bellouin, N., Benedetti, A., Bergman, T., Berntsen, T. K., Beukes, J. P., Bian, H., Carslaw, K. S., Chin, M., Curci, G., Diehl, T., Easter, R. C., Ghan, S. J., Gong, S. L., Hodzic, A., Hoyle, C. R., Iversen, T., Jathar, S., Jimenez, J. L., Kaiser, J. W., Kirkevåg, A., Koch, D., Kokkola, H., Lee, Y. H., Lin, G., Liu, X., Luo, G., Ma, X., Mann, G. W., Mihalopoulos, N., Morcrette, J.-J., Müller, J.-F., Myhre, G., Myriokefalitakis, S., Ng, N. L., O’Donnell, D., Penner, J. E., Pozzoli, L., Pringle, K. J., Russell, L. M., Schulz, M., Sciare, J., Seland, Ø., Shindell, D. T., Sillman, S., Skeie, R. B., Spracklen, D., Stavrakou, T., Steenrod, S. D., Takemura, T., Tiitta, P., Tilmes, S., Tost, H., van Noije, T., van Zyl, P. G., von Salzen, K., Yu, F., Wang, Z., Wang, Z., Zaveri, R. A., Zhang, H., Zhang, K., Zhang, Q., and Zhang, X.: The AeroCom evaluation and intercomparison of organic aerosol in global models, Atmos. Chem. Phys., 14, 10845-10895, https://doi.org/10.5194/acp-1410845-2014, 2014.

Twomey, S.: The nuclei of natural cloud formation. II The supersaturation in natural clouds and the variation of cloud droplet concentration, Geofis. Pura Appl., 43, 243-249, 1959.

Twomey, S.: The Influence of Pollution on the Shortwave Albedo of Clouds, J. Atmos. Sci. 34, 1149-1152, https://doi.org/10.1175/15200469(1977)034<1149:TIOPOT>2.0.CO;2, 1977.

Vehkamäki, H.: An improved parameterization for sulfuric acid-water nucleation rates for tropospheric and stratospheric conditions, J. Geophys. Res., 107, 4622, https://doi.org/10.1029/2002JD002184, 2002.

Vignati, E., Wilson, J., and Stier, P.: M7: An efficient sizeresolved aerosol microphysics module for large-scale aerosol transport models, J. Geophys. Res.-Atmos., 109, D22202, https://doi.org/10.1029/2003JD004485, 2004. 
Wang, H., Easter, R. C., Rasch, P. J., Wang, M., Liu, X., Ghan, S. J., Qian, Y., Yoon, J.-H., Ma, P.-L., and Vinoj, V.: Sensitivity of remote aerosol distributions to representation of cloud-aerosol interactions in a global climate model, Geosci. Model Dev., 6, 765-782, https://doi.org/10.5194/gmd-6-765-2013, 2013.

Yoshioka, M., Regayre, L. A., Pringle, K. J., Johnson, J. S., Mann, G. W., Partridge, D. G., Sexton, D. M. H., Lister, G. M. S., Schutgens, N.,Stier, P., Kipling, Z., Bellouin, N., Browse, J., Booth, B. B. B., Johnson, C. E.,Johnson, B., Mollard, J. D. P., Lee, L., and Carslaw, K. S.: Ensembles of Global Climate Model Variants Designed for the Quantification and Constraint of Uncertainty in Aerosols and their Radiative Forcing, J. Adv. Model. Earth Syst., under review, 2019.
Yu, F.: A secondary organic aerosol formation model considering successive oxidation aging and kinetic condensation of organic compounds: global scale implications, Atmos. Chem. Phys., 11, 1083-1099, https://doi.org/10.5194/acp-11-1083-2011, 2011.

Yu, F. and Luo, G.: Simulation of particle size distribution with a global aerosol model: contribution of nucleation to aerosol and CCN number concentrations, Atmos. Chem. Phys., 9, 76917710, https://doi.org/10.5194/acp-9-7691-2009, 2009.

Yu, F., Nadykto, A. B., Herb, J., Luo, G., Nazarenko, K. M., and Uvarova, L. A.: $\mathrm{H}_{2} \mathrm{SO}_{4}-\mathrm{H}_{2} \mathrm{O}-\mathrm{NH}_{3}$ ternary ion-mediated nucleation (TIMN): kinetic-based model and comparison with CLOUD measurements, Atmos. Chem. Phys., 18, 17451-17474, https://doi.org/10.5194/acp-18-17451-2018, 2018. 